\title{
Circulation characteristics of a monsoon depression during BOBMEX-99 using high-resolution analysis
}

\author{
Ananda K Das, U C Mohanty, Someshwar Das ${ }^{1}$, M Mandal and S R Kalsi ${ }^{2}$ \\ Center for Atmospheric Sciences, Indian Institute of Technology, Hauz Khas, New Delhi 110 016, India \\ ${ }^{1}$ National Center for Medium Range Weather Forecasting, Mausam Bhavan, Lodhi Road, New Delhi 110003. \\ ${ }^{2}$ India Meteorological Department, Mausam Bhavan, Lodhi Road, New Delhi 110003.
}

The skill and efficiency of a numerical model mostly varies with the quality of initial values, accuracy on parameterization of physical processes and horizontal and vertical resolution of the model. Commonly used low-resolution reanalyses are hardly able to capture the prominent features associated with organized convective processes in a monsoon depression. The objective is to prepare improved high-resolution analysis by the use of MM5 modelling system developed by the Pennsylvania State University/National Center for Atmospheric Research (PSU/NCAR). It requires the objective comparison of high and low-resolution analysis datasets in assessing the specific convective features of a monsoon depression. For this purpose, reanalysis datasets of NCAR/NCEP (National Center for Atmospheric Research/National Centers for Environmental Prediction) at a horizontal resolution of $2.5^{\circ}$ (latitude/longitude) have been used as first guess in the objective analysis scheme. The additional asynoptic datasets obtained during BOBMEX-99 are utilized within the assimilation process. Cloud Motion Wind (CMW) data of METEOSAT satellite and SSM/I surface wind data are included for the improvement of derived analysis. The multiquadric (MQD) interpolation technique is selected and applied for meteorological objective analysis at a horizontal resolution of $30 \mathrm{~km}$. After a successful inclusion of additional data, the resulting reanalysis is able to produce the structure of convective organization as well as prominent synoptic features associated with monsoon depression. Comparison and error verifications have been done with the help of available upper-air station data. The objective verification reveals the efficiency of the analysis scheme.

\section{Introduction}

Model initializations require regular grided approximation of observations. Regular grid representation of observations is also needed for the traditional computations in diagnostic study. The process, which transforms irregularly spaced scattered observational data to produce a data set on a regularly arranged grid, is commonly known as "objective analysis". This is the foremost and crucial part of the data assimilation cycle in a numerical model. An objective analysis scheme should be capable enough to perform several functions e.g. removal of erroneous data, interpolation, smooth- ing and some method to insure internal consistency among meteorological variables. Computational efficiency is also a key factor in the context of numerical weather prediction. Many significant methods have been devised to represent scattered data on a uniform grid. The method of successive corrections was introduced by Cressman (1959). Attempts to fit global atmospheric observation through multivariate functions (Hough functions) have been made by Halberstam and Tung (1984). The variational method of incorporating dynamic constraints in space (Sasaki 1958) as well as in time (Sasaki 1969) has been used for the analysis and assimilation of atmospheric observations.

Keywords. BOBMEX; high-resolution analysis; monsoon depression; MM5. 
Talagrand and Courtier (1987) used simple adjoint models for variational assimilation, which is mathematically proper and a rigorous way to achieve the goal. But for the complexity and heuristical assignments associated in this method its usage is still not adequate in numerical weather modeling. Among different methods, optimum (statistical) interpolation (OI) has been found to be very useful in GCMs due to the applicability in objective analysis (Schlatter 1975; Lorenc 1981). The spectral statistical interpolation (SSI) technique in the analysis system is most widely used for the global models in several operational NWP centers (e.g., Parrish and Derber 1992). However, the usefulness of OI and SSI methods, precisely for local (limited area) high-resolution analysis is limited by the computational expense and complexity in real applications. Especially, for the high-resolution analysis of special sets of observations from field experiments and satellite observations, the meteorological community often uses Barnes (1964) or Cressman (1959) techniques of successive corrections. The study by Benjamin and Seaman (1985) shows that these schemes have strong scale dependency, as mesh size is decreased, which introduces relatively large errors. Hardy (1971) developed a mathematical method referred to as multiquadric interpolation that produces a more accurate analysis. This method has been implemented for actual meteorological implications by Nuss and Titley (1994). This paper mainly describes the multiquadric technique and demonstrates its application in the highresolution analysis. A study has been done on a monsoon depression, a weather phenomena characterized by its particular features of organized convection.

A simple illustration on response characteristics of this analysis scheme is given on the basis of comparison between standard low-resolution NCEP reanalysis and resulting high-resolution analysis.

\section{Multiquadric interpolation theory}

Use of 'basis functions' is the basis of general theory of interpolation. Multiquadric as well as statistical interpolation techniques utilize radial basis functions to fit all significant observational data that provides a logical interpolation at intermediate regular grid points in resulting analysis. Caracena (1987) also followed the same technique. The choice of basis functions and their mathematical framework varies among different methods. The multiquadric method uses hyperboloid functions as the basis functions. The interpolation equation can be written as

$$
H(X)=\sum_{i=1}^{N} \alpha_{i} Q\left(X-X_{i}\right)
$$

where

$$
Q\left(X-X_{i}\right)=-\left(\frac{\left\|X-X_{i}\right\|^{2}}{c^{2}}+1.0\right)^{1 / 2} .
$$

$H(X)$ is a spatially varying field, $Q\left(X-X_{i}\right)$ is a radial basis function and the arguments $X, X_{i}$ represent the position vector of any point and observation point respectively. The co-efficient $\alpha_{i}$ are weighting factors and $c$ is an arbitrary small constant referred as multiquadric parameter.

The hyperboloid function in two dimensions becomes

$$
Q_{i}(x, y)=-\left(\frac{\left|x-x_{i}\right|^{2}+\left|y-y_{i}\right|^{2}}{c^{2}}+1.0\right)^{1 / 2}
$$

Applying the interpolation equation at every observation point $\left(x_{j}, y_{j}\right)$ we get

$$
H\left(x_{j}, y_{j}\right)=\sum_{i=1}^{N} \alpha_{i} Q_{i}\left(x_{j}, y_{j}\right) .
$$

So, the co-efficient $\alpha_{i}$ can be determined by solving a set of linear equations.

In this paper, field variables $H\left(x_{j}, y_{j}\right)$ are the deviation of the observations from some background field. In matrix notation, equation (4) becomes

$$
\mathbf{H}_{j}=\mathbf{Q}_{i j} \alpha_{i} .
$$

So, the solution for $\alpha_{i}$ can be written mathematically as

$$
\alpha_{i}=\mathbf{Q}_{i j}^{-1} \mathbf{H}_{j} .
$$

The solutions for the field variables are required on uniform grid points $\left(x_{g}, y_{g}\right)$ represented by $\mathbf{H}_{g}$. So,

$$
\mathbf{H}_{g}=\mathbf{Q}_{g i} \mathbf{Q}_{i j}^{-1} \mathbf{H}_{j} .
$$

The matrix $\mathbf{Q}_{g i}$ is not a square matrix as numbers of observations differ from number of grid points. The expression for $\mathbf{Q}_{g i}$ is given by

$$
Q_{g i}=-\left(\frac{\left|x_{g}-x_{i}\right|^{2}+\left|y_{g}-y_{i}\right|^{2}}{c^{2}}+1.0\right)^{1 / 2} .
$$

The solution on the grid points of any arbitrary spacing can be computed once the determination of the co-efficient $\alpha_{i}$ is over. 
Though, this is a very accurate interpolation for the solution, its direct application to the meteorological application have problems. The observational errors as well as incomplete sampling of small-scale features may lead to unrealistic analysis. The quality control checks over observational data from different soures minimize erroneous data points. The smoothing or filtering of unresolved scales from the analysis is also a necessary aspect in this regard. So, a modification of interpolation equation gives

$$
\mathbf{H}_{j}=\left[\mathbf{Q}_{i j}+\left(N \lambda \sigma_{i}^{2} \delta_{i j}\right)\right] \alpha_{i},
$$

where $N$ is the number of observations, $\sigma_{2}^{i}$ is the mean squared observational error (compared to first guess), $\lambda$ is a smoothing parameter controlling the degree of smoothing and $\delta_{i j}$ is the Kronecker delta, which only modify $\mathbf{Q}_{i j}$ matrix changing the diagonal elements. In this study, the value of $\lambda$ is set to unity.

\section{Data}

A monsoon depression of July 1999 has been considered in this study. The whole depression event has been studied thoroughly during the first leg of BOBMEX-99 experiment. The depression was at its mature stage at 12 UTC on 27th July 1999. Hence, observations at this time have been selected for analysis. During this time the depression intensified into deep depression and centered near $22.0^{\circ} \mathrm{N}$ and $88.5^{\circ} \mathrm{E}$ close to Sand Heads just before landfall (Thapliyal et al 2000).

The meteorological data sets used in this study have been grouped in two categories. A lowresolution $\left(2.5^{\circ} \times 2.5^{\circ}\right)$ reanalysis $(\mathrm{NCEP} / \mathrm{NCAR})$ data set has been used as a first guess. All meteorological observations (routine/special) collected and used, come in the second category. Routine upper-air observations at 12 UTC, 27th July 1999 covering the Indian subcontinent have been considered for high-resolution analysis, although those observations have also been utilized for the preparation of first guess reanalysis. The locations of observing stations for upper-air RS/RW data are shown in figure 1(a). The position of the ship ORV Sagar Kanya (taking special observation for BOBMEX-99) during the specified time is also indicated in the same figure. Significant observations from geo-stationary satellite (METEOSAT) has provided with cloud motion winds (CMWs) and cloud top temperatures as shown in figure 1(b). The SSM/I surface wind data at a resolution of $75 \mathrm{~km}$ have been utilized in the analysis procedure. Figure 1(c) represents the area coverage of $\mathrm{SSM} / \mathrm{I}$ wind data.

\section{Results and discussions}

The horizontal and vertical structures of monsoon depression represent the forcing of large-scale circulations by embedded deep convection. A "feature specific" investigation has been carried out in this paper to cover several distinct features of monsoon depression, which together constitute and modulate the horizontal as well as vertical structure of the system. The horizontal flow characteristics at different pressure levels have been considered separately for a comparative study between two analyses (NCEP reanalysis and high-resolution analysis). Then a discussion on vertical structure (zonal and meridional) follows to put a consequence in the description of interplaying mechanisms of the system. A qualitative verification of the prominent features of a monsoon depression has been stated objectively. The meteorological fields of low-resolution NCEP reanalysis are interpolated to the resolution of final high-resolution analysis $(30 \mathrm{~km})$ through bi-linear interpolation, and all comparisons are made between resulting high-resolution analysis and interpolated NCEP reanalysis.

\subsection{Horizontal structure}

\subsubsection{Mean sea level pressure}

The mean sea level pressure (MSLP) field of the monsoon depression from the NCEP reanalysis and high-resolution analysis is shown in figure 2(a) and 2 (b) respectively. Comparing figure 2(a) and 2(b), it is noticed that mean sea level pressure patterns are similar in both the analysis and depression has the same central pressure of $994 \mathrm{hPa}$. The center of the storm at $\left(22^{\circ} \mathrm{N}, 88^{\circ} \mathrm{E}\right)$ is nicely embedded in the monsoon trough and placed at the southeastern end. Evidently, the monsoon depression is an intense synoptic scale low-pressure system and the organization of its deep convective components cannot change the pressure pattern in its mature stage but orient them duly keeping coherence (Krishnamurti et al 1998). Moreover, surface observations from GTS data are not included in the resultant high-resolution analysis. Only wind speed observations from SSM/I satellite covering a part of Indian seas are not adequate for the analysis over the whole domain.

\subsubsection{Winds}

Figure 3 describes the wind field at different pressure levels $(850,500$ and $200 \mathrm{hPa})$ in NCEP and high-resolution analysis. The streamlines represent a well-defined cyclonic circulation in the lower and middle troposphere. The westerly flow in the 


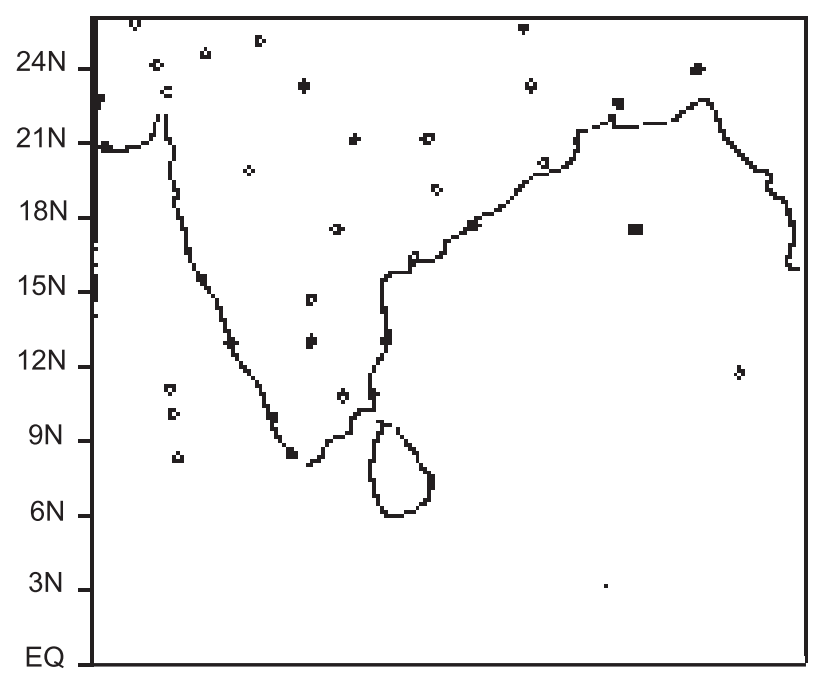

(a)

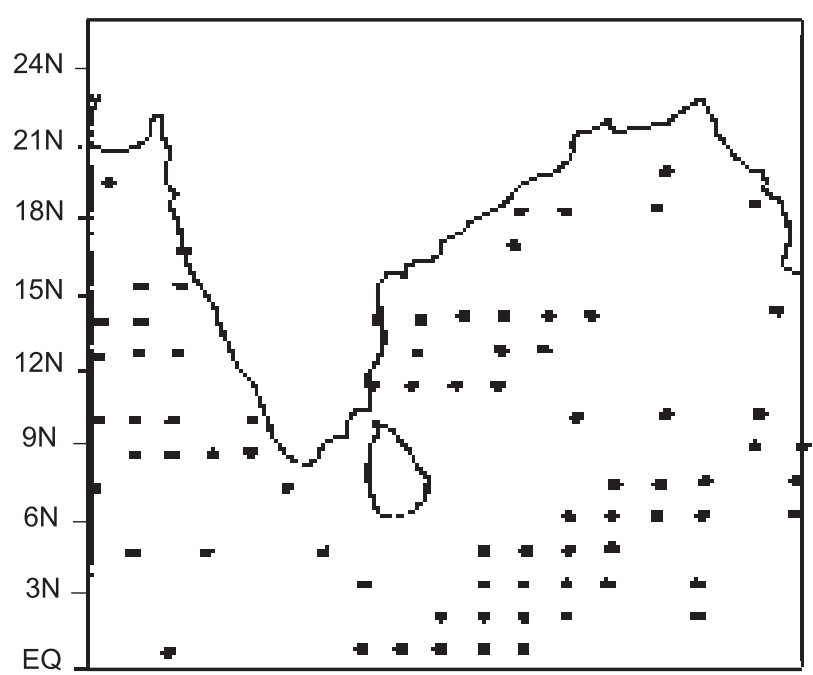

(b)

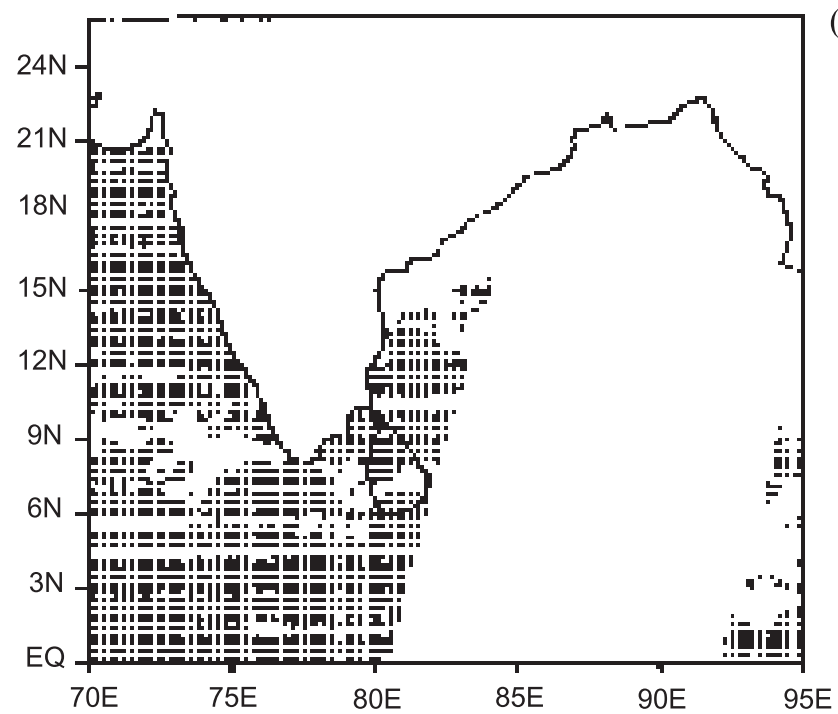

(c)

○ - RS/RW Land Stations

9 - ORV Sagarkanya

- METEOSAT Data

[!!!咕 - SSM/I Data

Figure 1. Observations used for the high-resolution analysis. (a) Upper-air observations, (b) Cloud motion winds (CMWs) and cloud top temperature, (c) SSM/I surface wind speed. 
a) NCEP

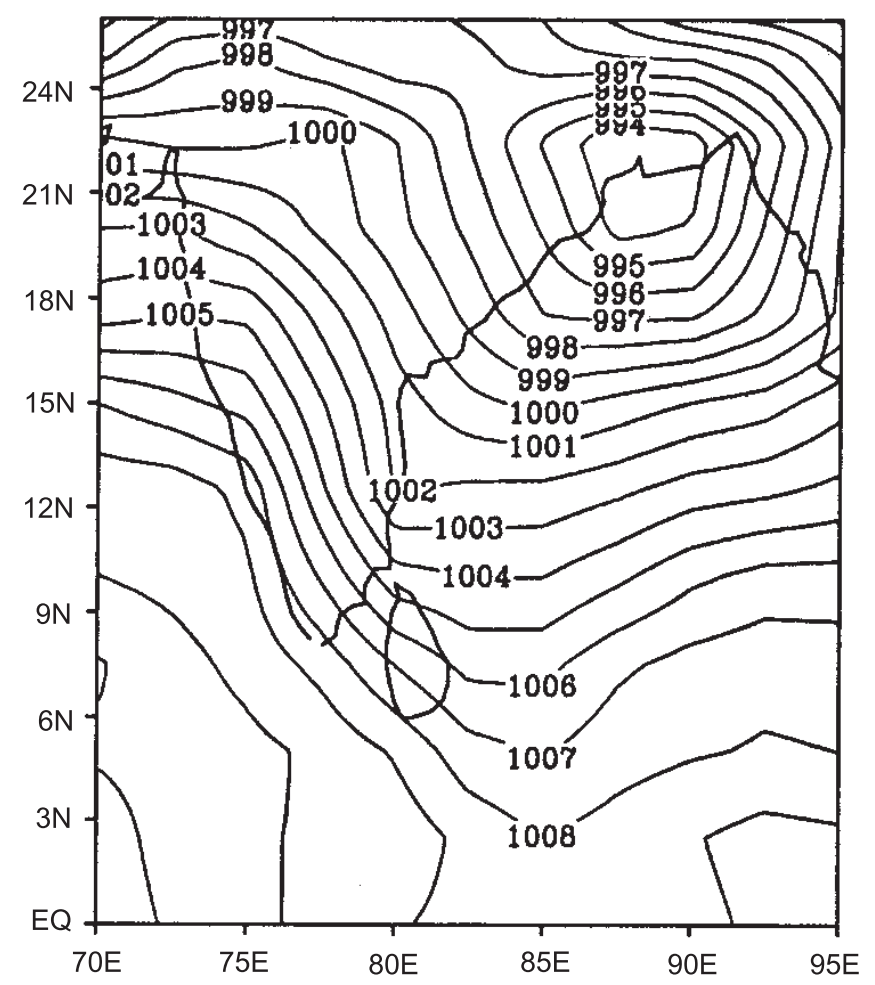

b) HRES ANALYSIS

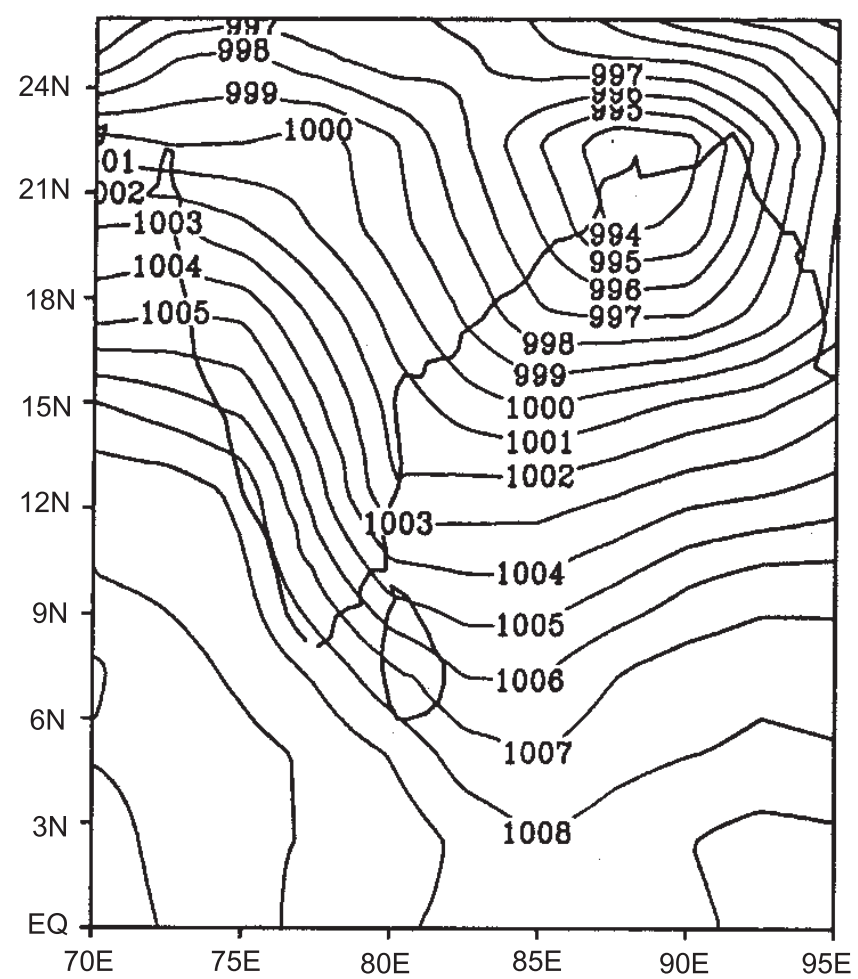

Figure 2. Mean sea level pressure in hPa. (a) NCEP reanalysis and (b) High-resolution analysis. 
a) $850 \mathrm{hPa}$ (NCEP)

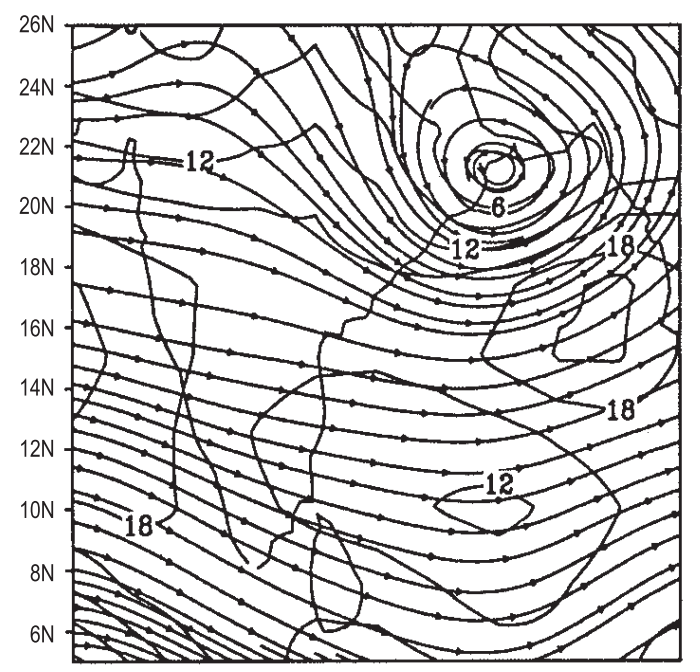

c) $500 \mathrm{hPa}(\mathrm{NCEP})$

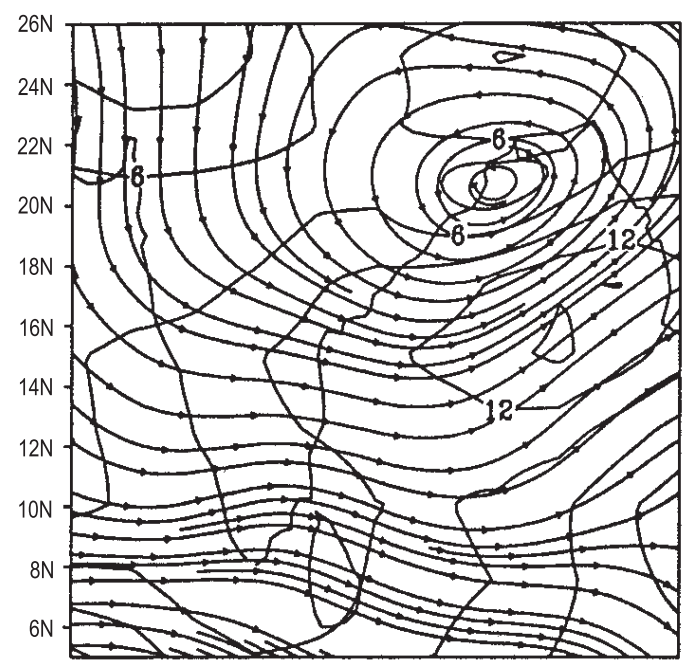

e) $200 \mathrm{hPa}(\mathrm{NCEP})$

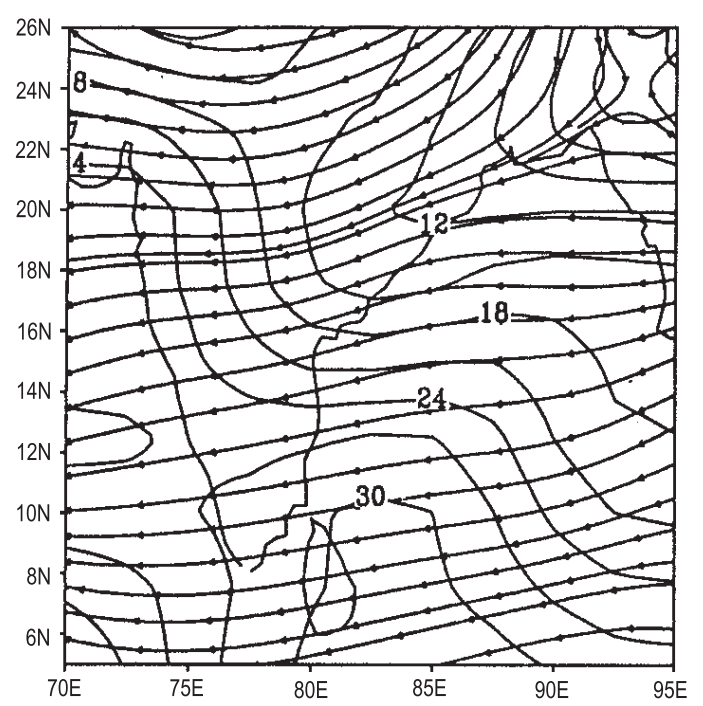

b) $850 \mathrm{hPa}$ (HRES)

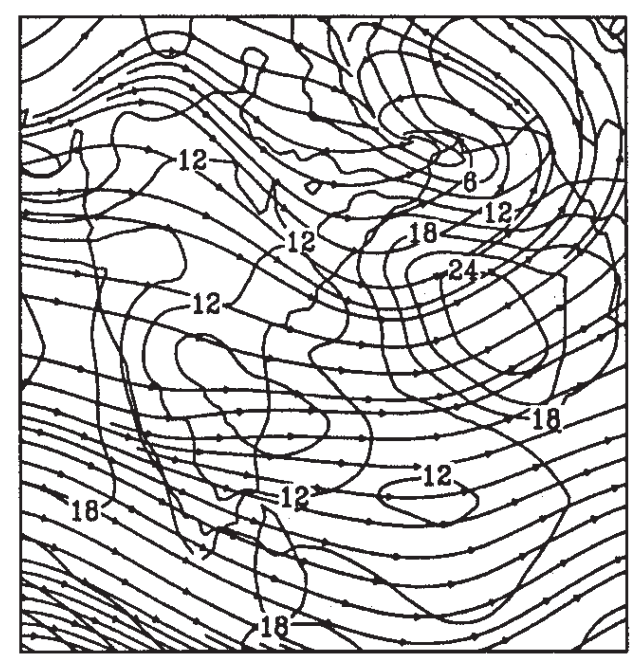

d) $500 \mathrm{hPa}$ (HRES)

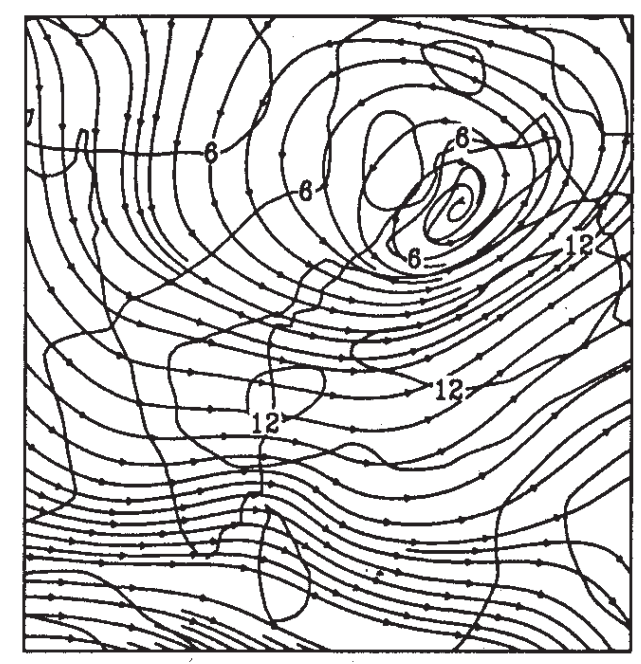

f) $200 \mathrm{hPa}$ (HRES)

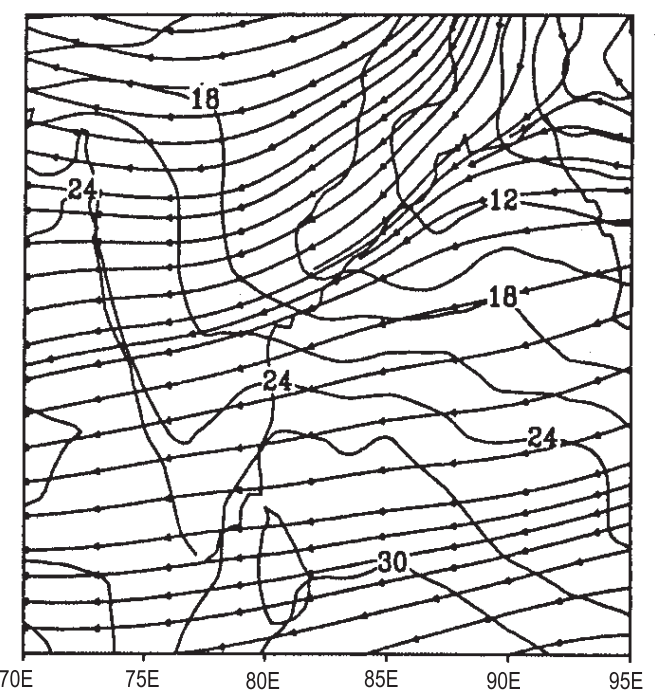

Figure 3. Streamlines and isotachs $\left(\mathrm{ms}^{-1}\right)$ at different pressure levels. (a) NCEP reanalysis at $850 \mathrm{hPa}$, (b) High-resolution analysis at $850 \mathrm{hPa}$, (c) NCEP reanalysis at $500 \mathrm{hPa}$, (d) High-resolution analysis at $500 \mathrm{hPa}$, (e) NCEP reanalysis at $200 \mathrm{hPa}$ and (f) High-resolution analysis at $200 \mathrm{hPa}$. 
south-southwest sector of the depression system is stronger in the high-resolution analysis compared to NCEP reanalysis. The wind flow pattern shows a vertical symmetry in the NCEP reanalysis (figure 3 (a) and (c)) and there is no shifting of the center position from $850 \mathrm{hPa}$ level to $500 \mathrm{hPa}$ level. In the high-resolution analysis, the wind field shows an asymmetry and the center at $850 \mathrm{hPa}$ is shifted more inland as compared to NCEP reanalysis (figure 3 (a) and (b)). Figure 3(d) indicates that the center of the circulation at $500 \mathrm{hPa}$ is located over the Bay of Bengal to the southeast of $850 \mathrm{hPa}$ position (figure $3(\mathrm{~b})$ ). Therefore, the vertical axis of the storm in high-resolution analysis tilts southeastward with height. This wellestablished feature of monsoon depression is clearly mentioned by Keshavamurty and Rao (1992) in his book on monsoon. Figure 3(e) and 3(f) show that the flow in the upper troposphere is easterly and dominated and maintained by the Tibetan high. The shear zone is pushed towards the equator, as the return flow of monsoon is stronger in high-resolution analysis compared to NCEP analysis.

\subsubsection{Vorticity and divergence}

The relative vorticity and divergence fields are plotted in figure 5 and figure 6 respectively. At $850 \mathrm{hPa}$ level, the cyclonic vorticity (shaded area) around the center of the depression is clearly shown in figure 4 (a) and (b). The regions of negative relative vorticity at the periphery of the depression are nearly absent in the case of NCEP reanalysis (figure 4(a)). But the anticyclonic gyres are clearly established in high-resolution analysis as expected from gradient wind considerations. At $400 \mathrm{hPa}$, the vorticity field pattern (with a maximum of $80 \times 10^{-6} \mathrm{~s}^{-1}$ ) is markedly different in the final high-resolution analysis compared to NCEP reanalysis. The center of cyclonic vorticity at this level is shifted towards southwest from its position at $850 \mathrm{hPa}$ and an anticyclonic vorticity cell is pulled at the northeast sector. The vertical momentum transport by deep convection creates vorticity couplets in the upper troposphere, which have no net circulation at larger scales (Mapes and Robert 1992).

In figure 5 (a) and (b), the divergence field shows that the high-resolution analysis portrayed a clear picture of the specified event whereas the NCEP reanalysis represents a void in this respect. A strong convergence (shaded region) at $850 \mathrm{hPa}$ around the center of the depression is extended along the monsoon trough. The maximum converging flow in the northwest sector of the storm that is shown in figure 5 (a) has also been studied by previous researchers (Godbole 1977). Intermediate divergence in between successive convergent zones is brought out well in the high-resolution analysis by the inclusion of additional data. Around the shifted center at $400 \mathrm{hPa}$, generation of symmetric divergence couplet is shown in figure $5(\mathrm{~b})$. The NCEP reanalysis is unable to produce this feature.

\subsection{Vertical structure}

\subsubsection{Winds}

Figure 6 (a) and (b) show the vertical cross section of the zonal component of wind ( $u$-component) along longitude $88.0^{\circ} \mathrm{E}$, whereas figure 6 (c) and (d) represent the vertical cross section of the meridional component of wind ( $v$-component) along latitude $22.0^{\circ} \mathrm{N}$. The diagrams show that the zonal circulation feature is very much symmetrical with height and weak in NCEP reanalysis. In the resultant high-resolution analysis, westerly flow at south as well as the easterly flow at the northern side of the center of the depression are stronger by a magnitude of $\pm 4 \mathrm{~ms}^{-1}$ compared to NCEP reanalysis. In the final analysis, the strongest westerly flow is seen near $850 \mathrm{hPa}$ pressure level but the strongest flow in the easterly cell is positioned near $700 \mathrm{hPa}$. A strong low-level westerly jet exists over the Indian subcontinent, which influences the circulation pattern of the monsoon depression in the lower levels. These features of low level jet and its interaction with the mountains in the Indian peninsular region were studied by $\mathrm{Wu}$ et al (1999) in their numerical investigation. Zonal cross section of $v$-component illustrates that the flow pattern in NCEP reanalysis is very much symmetrical around the axis, which is vertically straight. A weak northwesterly wind above the storm center is seen near $350 \mathrm{hPa}$. In the high-resolution analysis, the circulation in the western sector of the depression is not organized like the eastern sector. The maximum of northerly flow is located around $800 \mathrm{hPa}$ level while the southerly maximum is placed above $700 \mathrm{hPa}$ in the eastern and western sector respectively. This asymmetry is well supported by the earlier study of Godbole (1977). But the elongation of southerly cell and a westward shift is not explained yet, which might be a modulation in the flow pattern due to the high mountain barrier.

\subsubsection{Temperature}

The temperature field is represented by its anomaly, which is defined as the deviation from the latitudinal mean value. Thus, a positive anomaly represented by the shading in figure 7 , depicts a warmer area. The vertical cross sections of the temperature anomaly along longitude $88^{\circ} \mathrm{E}$ are shown in figure 7 (a) and (b) and the sectional plots along 

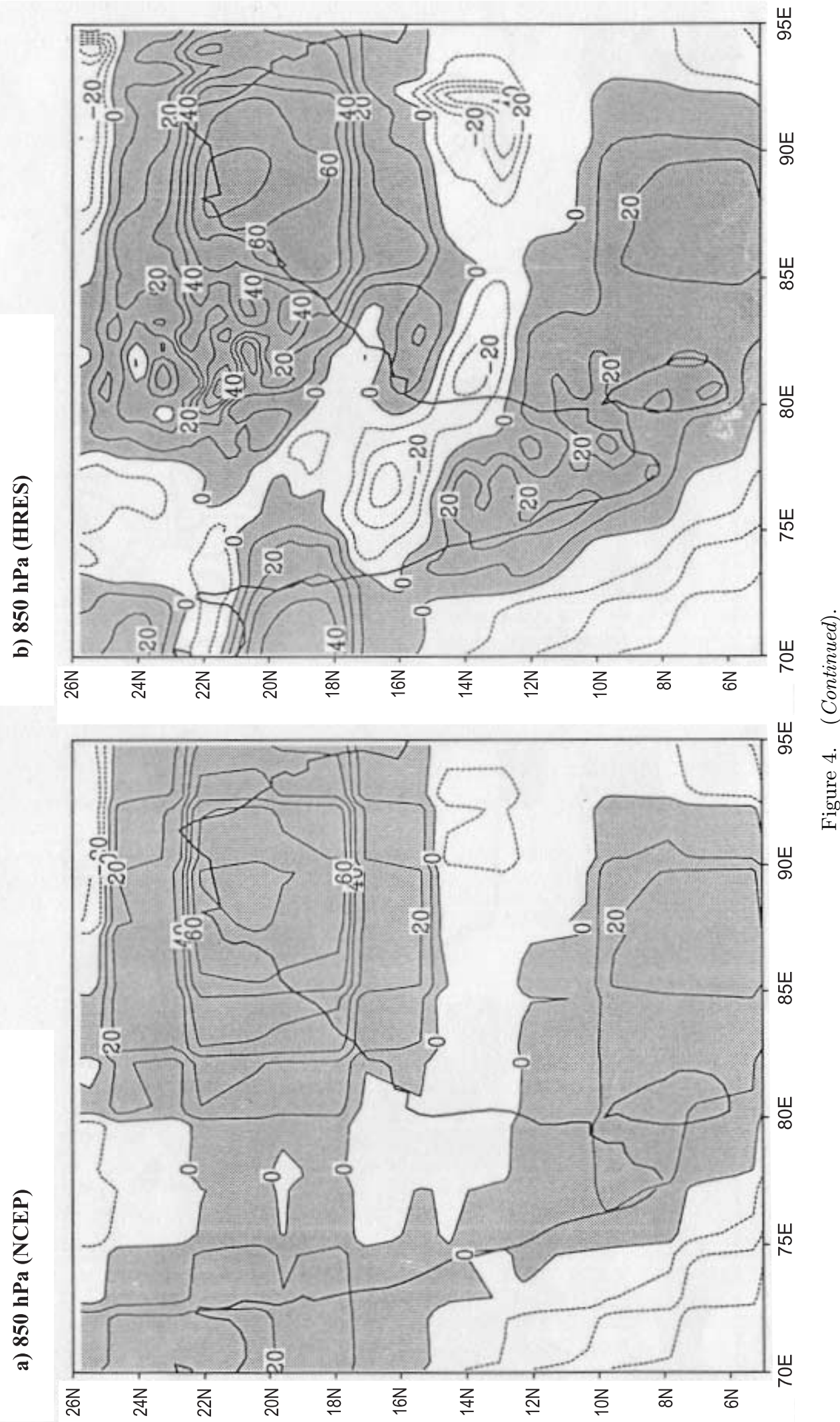

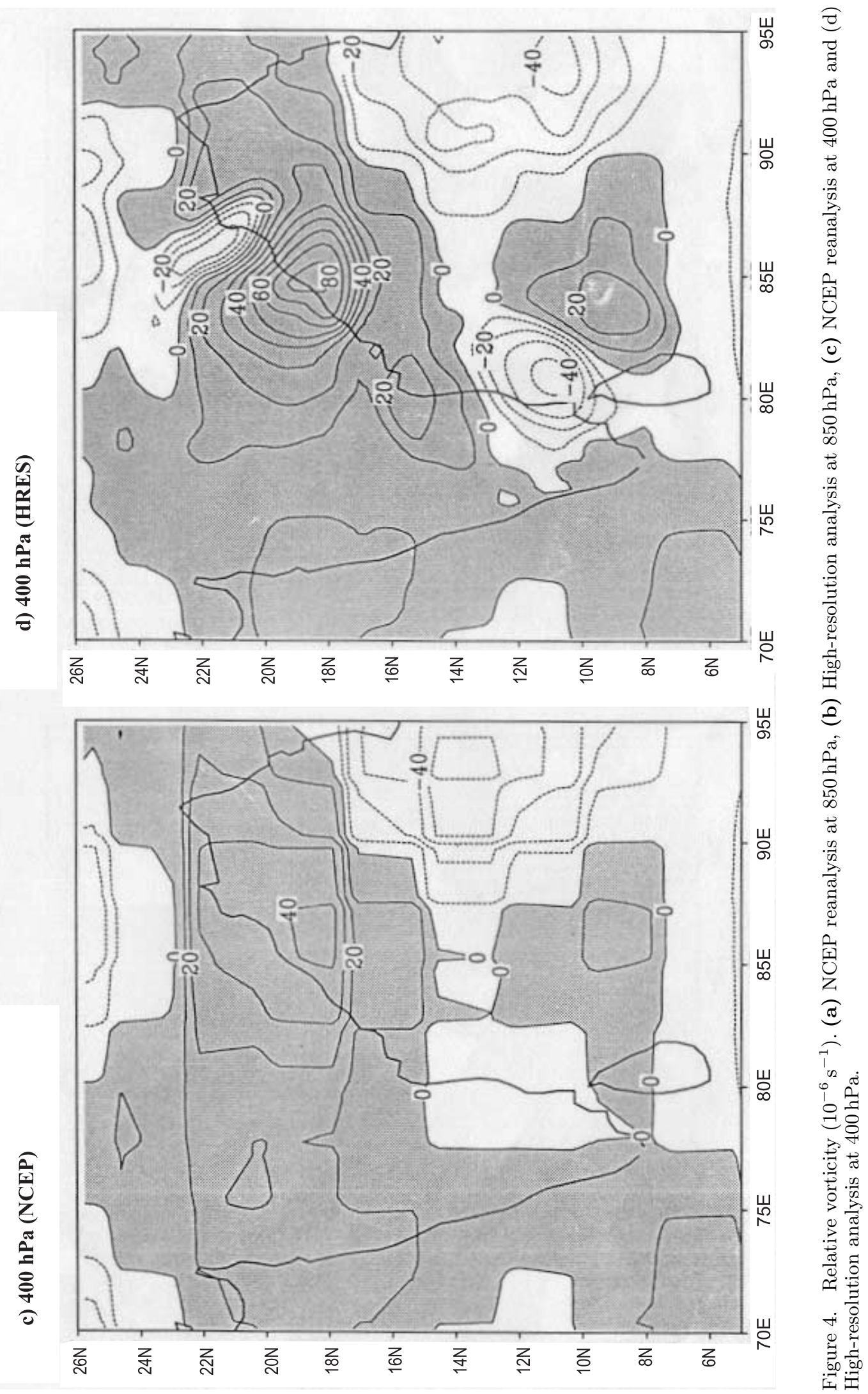

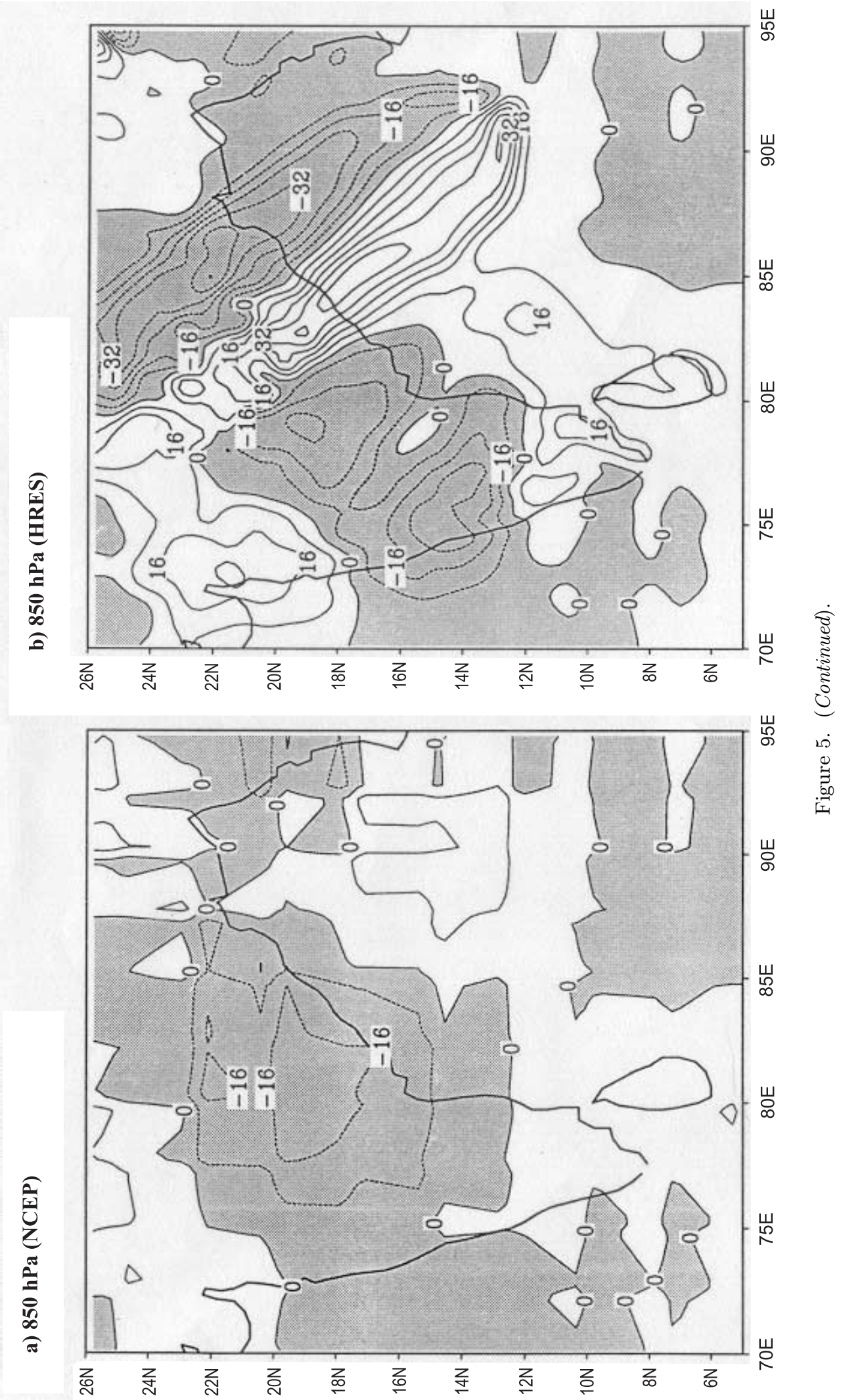

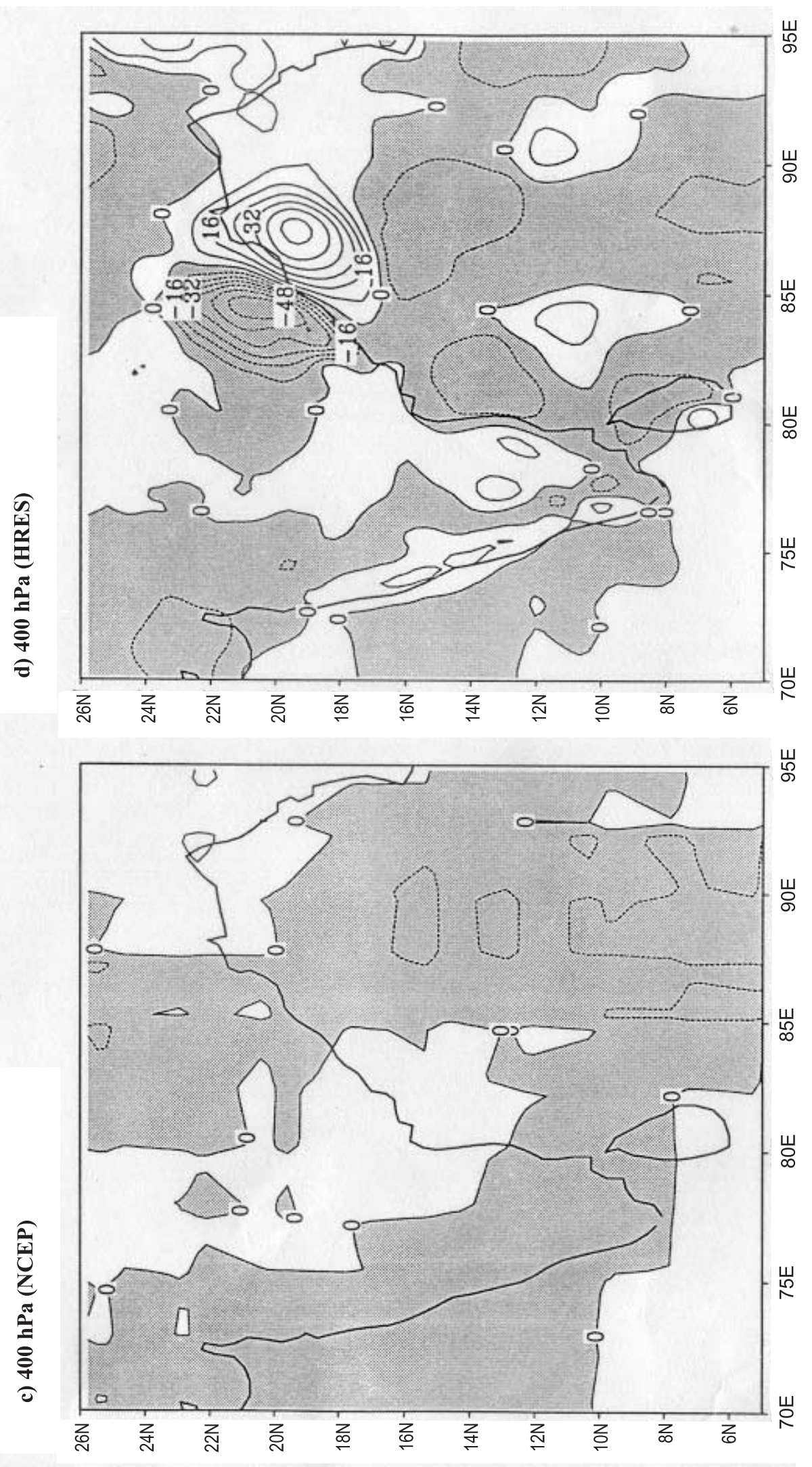

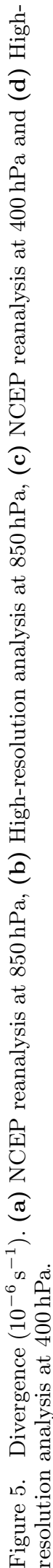


a) NCEP

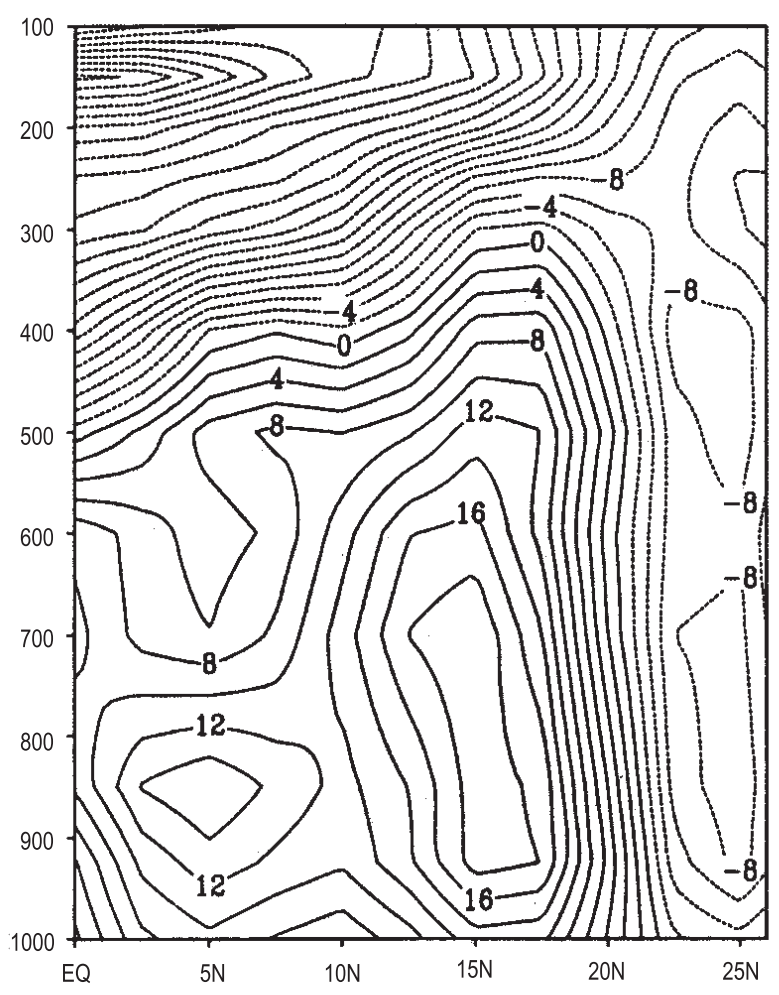

c) NCEP

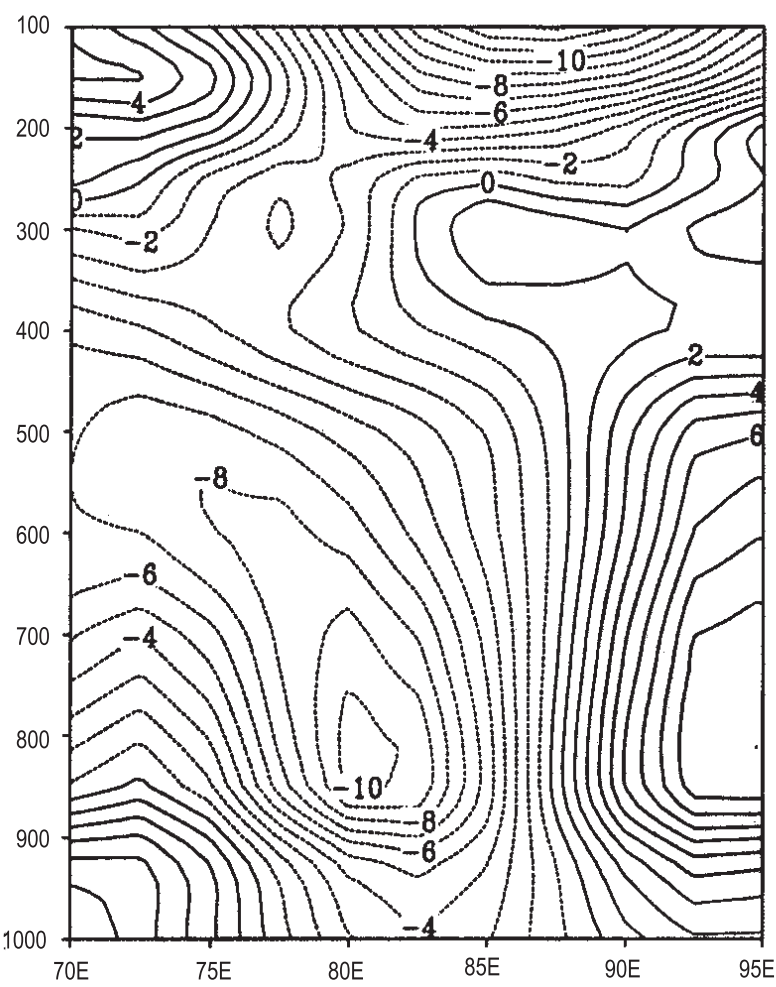

b) HRES

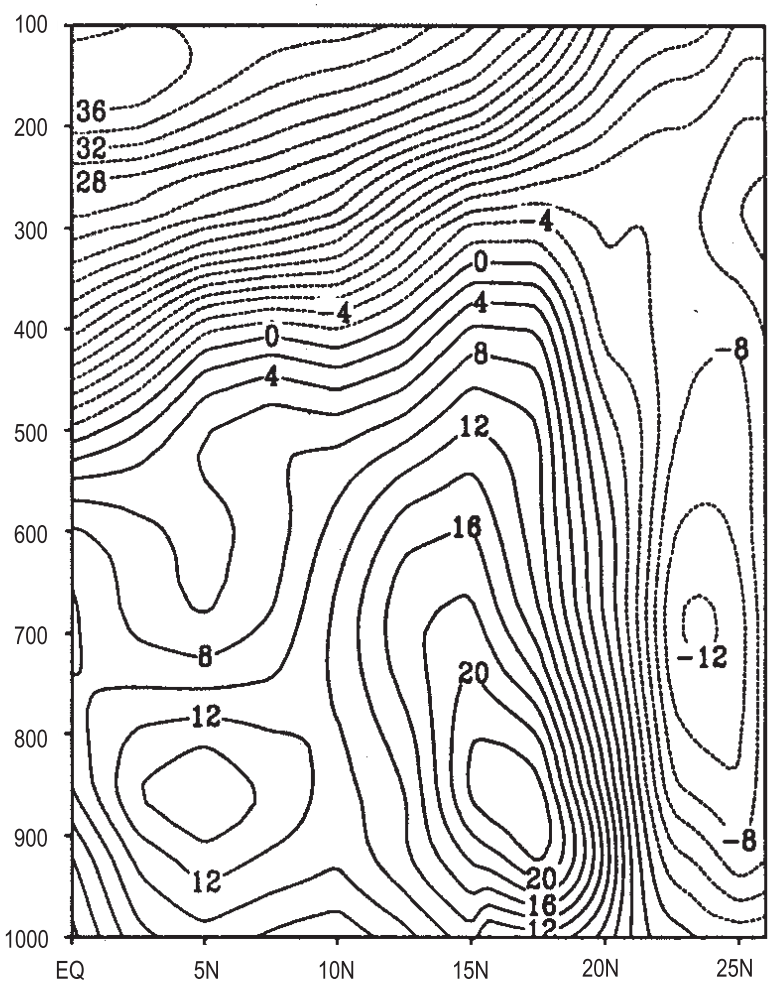

d) HRES

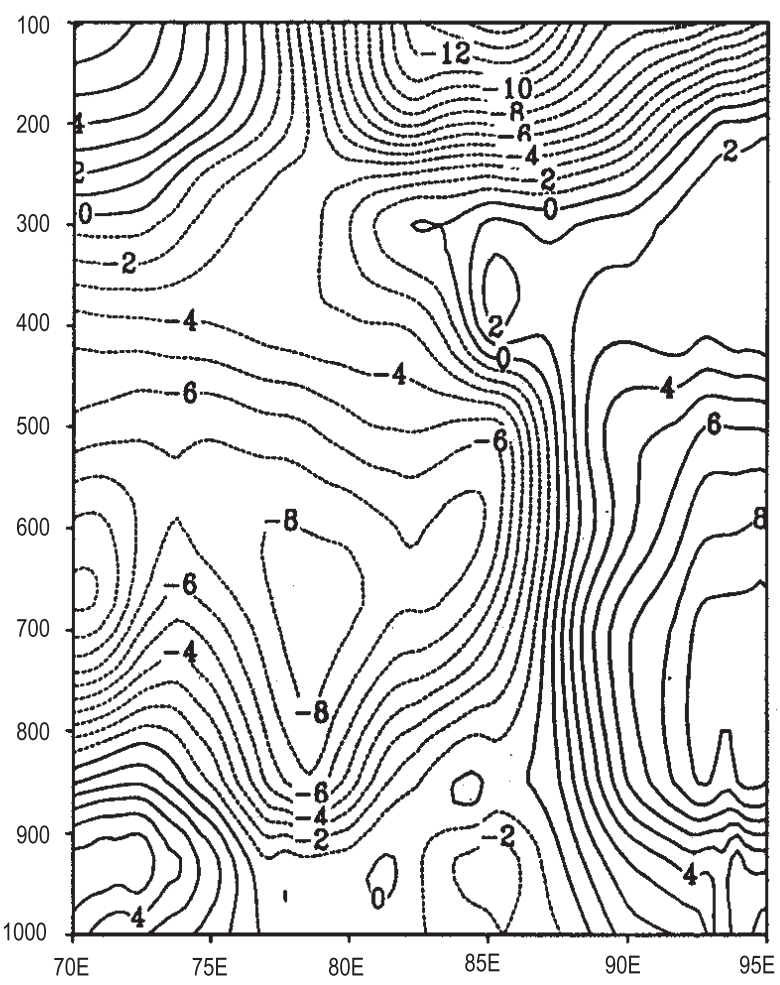

Figure 6. Vertical cross sections of wind components. (a) and (b) Meridional cross section of zonal wind (u-component) along $88.0^{\circ} \mathrm{E},(\mathbf{c})$ and (d) Zonal cross section of meridional wind (v-component) along $22.0^{\circ} \mathrm{N}$. 
a) NCEP

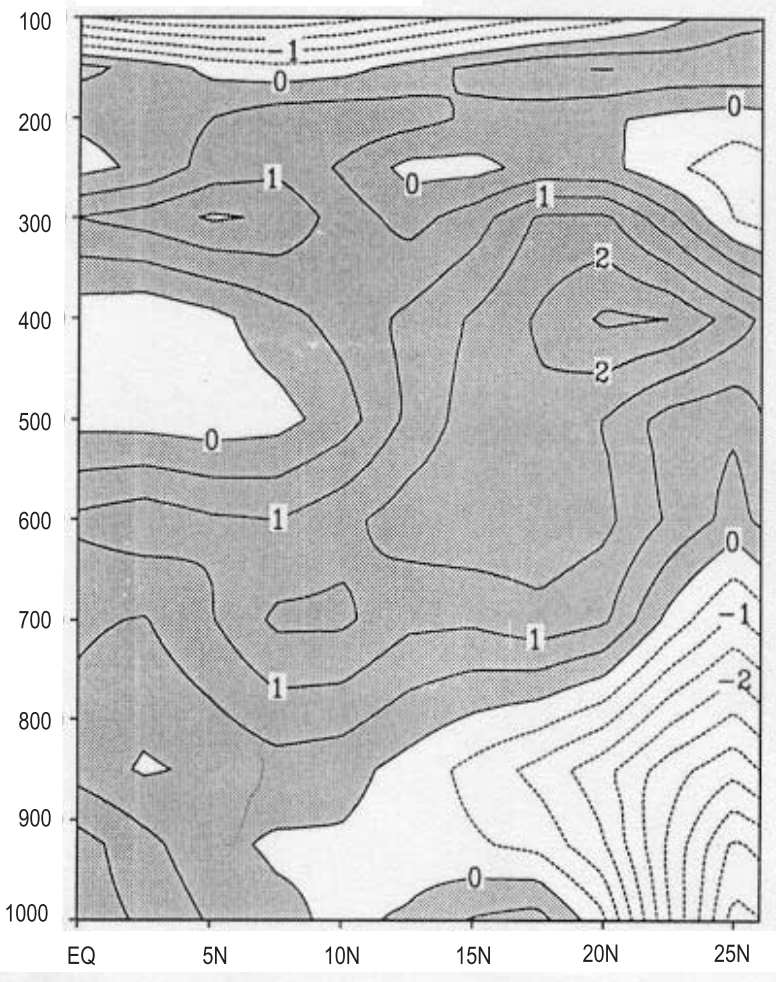

c) NCEP

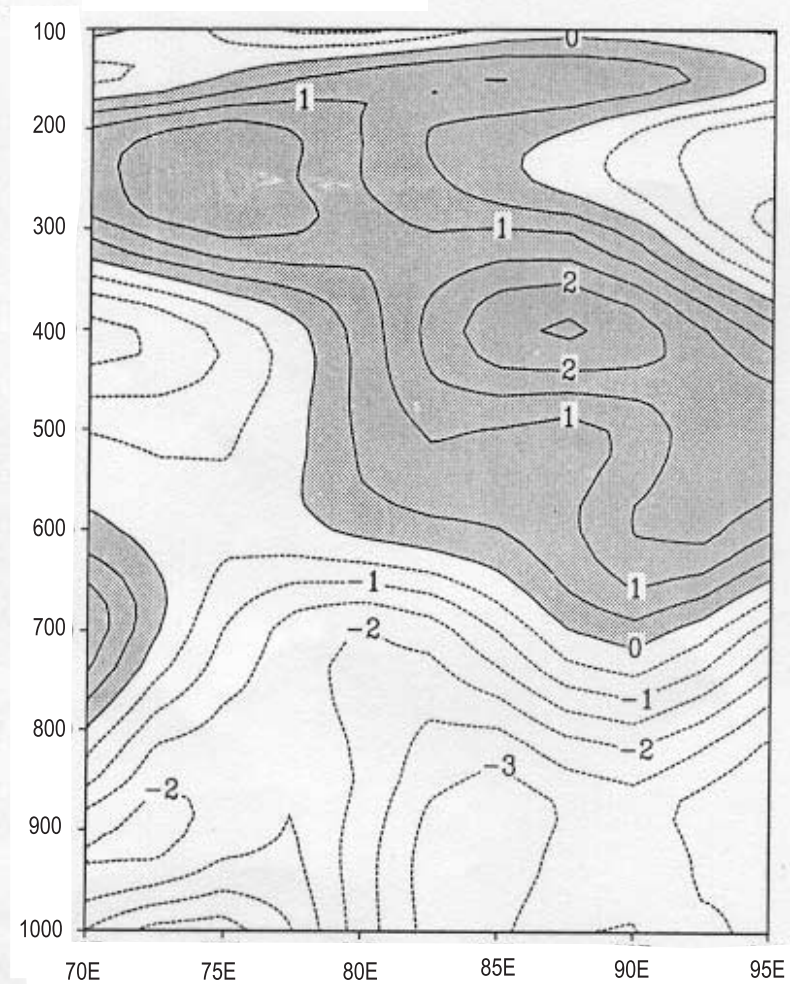

b) HRES

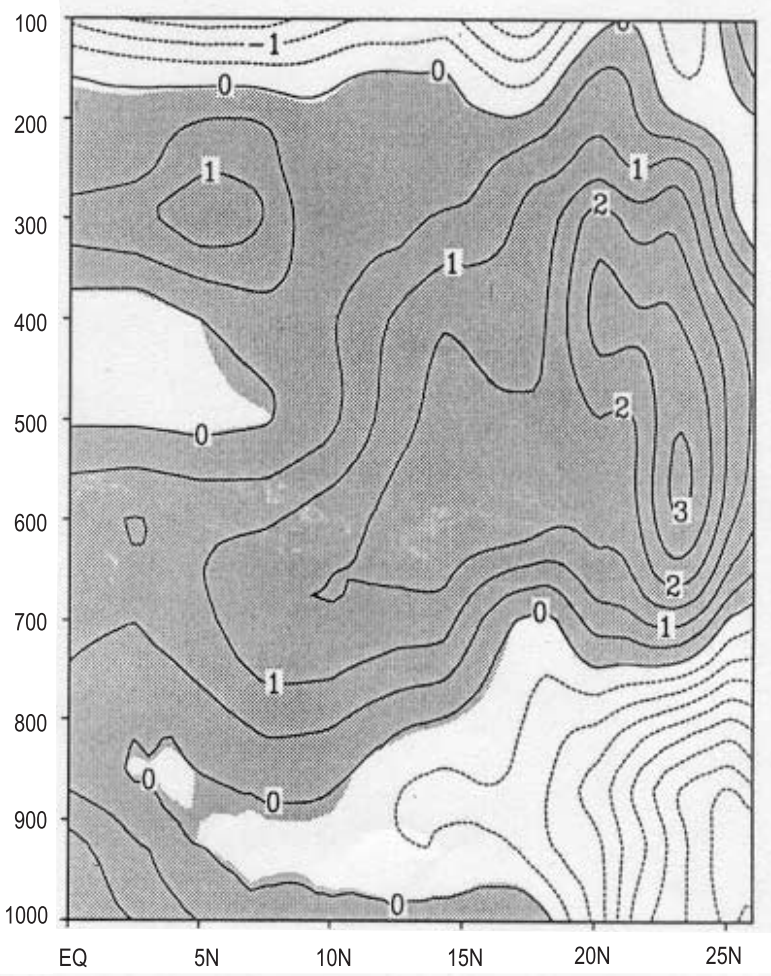

d) HRES

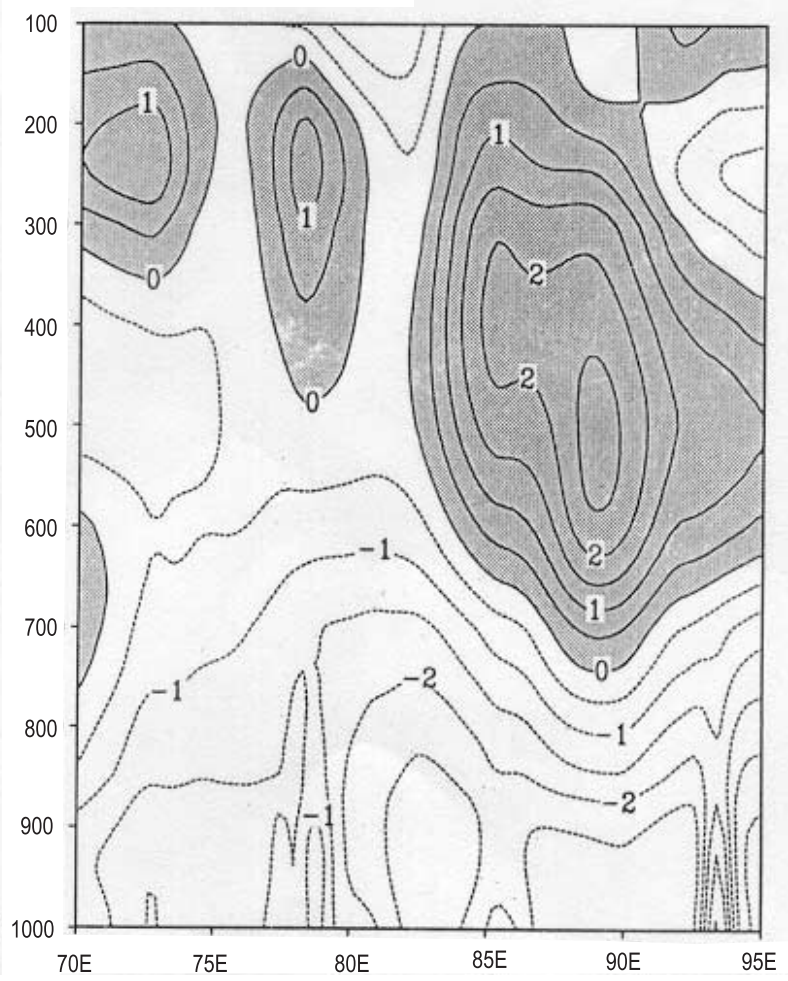

Figure 7. Vertical cross sections of temperature anomaly in degree Kelvin. (a) and (b) Meridional cross section along $88.0^{\circ} \mathrm{E}$, (c) and (d) Zonal cross sections along $22.0^{\circ} \mathrm{N}$. 
latitude $22^{\circ} \mathrm{N}$ are drawn in figure 7 (c) and (d). The plots for both NCEP reanalysis and final highresolution analysis are reproduced side by side in the same figure for easy comparison. In figure 7 (a)-(c), a cold core up to $700 \mathrm{hPa}$ is well defined in the analyses but the mid-tropospheric warming around the center of the depression is more distinct and pronounced in the high-resolution analysis (figure 7 (b) and (d)). Ramage also mentioned this feature in 1971. A strong convergence in the lower troposphere causes a strong updraft up to mid-troposphere. Henceforth, a large amount of latent heat due to condensation is released above $700 \mathrm{hPa}$, which in turn warms up the air, and strengthens the circulation. Cooling at lower levels is lower in the high-resolution analysis compared to NCEP reanalysis while mid-tropospheric warming is higher. As a result the circulation is stronger in the high-resolution analysis, which is also well supported by the vertical structure of divergence and vorticity fields in figures 8 and 9 respectively. Due to the extensive mid-tropospheric heating, the divergent flow at upper troposphere extends out to large distances, which is obvious in the lower panels of figures 8 and 9 . Therefore, localized deep convective heating spins up not only smaller scale vortices within the depression but also large-scale monsoon circulation.

\subsubsection{Vorticity and divergence}

The vertical cross-sections of relative vorticity and divergence fields along the longitude $88.0^{\circ} \mathrm{E}$ are shown in figure 8 (a) and (c). Two panels at the top illustrate the structural difference in the relative vorticity field between the two analyses. In the high-resolution analysis (figure 8(b)) cyclonic vorticity is stronger and the organization shows a positive vorticity center in the lower troposphere $(900 \mathrm{hPa})$, and a secondary maximum around $700 \mathrm{hPa}$. Contrary to this, NCEP reanalysis (figure 8) shows one maxima near $850 \mathrm{hPa}$. Intensification of the storm in the mid-troposphere sometimes causes a feeble subsidence zone at the center of the circulation, which splits vorticity structure, somewhat like the eye formation in tropical cyclone. The vertical structure of divergence field also shows a marked difference between the two analyses. A low level convergence near the storm center is well established in the highresolution analysis (figure 8(d)). A strong compensating divergent flow above the convergent zone is totally absent in the NCEP reanalysis (figure 8(c)). Further, the upper tropospheric divergence due to the return flow of the monsoon is also associated with the upper level divergence of the storm. The depression caused an induced divergent zone in the lower levels at the south of the storm center. This typical circulation feature provided by the high-resolution analysis is clear and distinct.

Figure 9 shows the vertical cross sections of relative vorticity and divergence along the latitude $22.0^{\circ} \mathrm{N}$. The cyclonic vorticity in the highresolution analysis is more intensified compared to NCEP reanalysis and the position of the maximum positive vorticity is also shifted upward above $800 \mathrm{hPa}$ pressure level. Comparison between the two analyses shows that the cyclonic circulation around the center of the storm is wide spread in the NCEP reanalysis, whereas it is confined in a narrow zone around the center in the high-resolution analysis. Figure 9 (c) and (d) represent the vertical structure of the divergence field for the NCEP reanalysis and the computed high-resolution analysis respectively. In the high-resolution analysis, the convergence in the low and middle troposphere over the Indian sub-continent due to monsoon depression is distinctly placed near the center of the storm. But, NCEP reanalysis shows a continuous zone of convergence surrounding the depression. It is clearly seen that the upper level divergence of the storm as well as the divergence in the upper troposphere due to return flow of the monsoon is nicely produced by the high-resolution analysis. Figure 8(d) also resembled the same feature.

\section{Quantitative verifications}

The feature specific study till now has revealed that the high-resolution analysis is capable of describing the circulation characteristics of a monsoon depression in a better way as compared to a lowresolution analysis. In this section, a quantitative investigation has been carried out with the help of upper-air observations collected at some land stations. The vertical profiles of basic meteorological variables e.g., zonal $(u)$ and meridional $(v)$ component of the wind, equivalent potential temperature (EPT) and relative humidity $(\mathrm{RH})$ are computed at selected observation points from both the analyses through interpolation. Two stations have been selected for this purpose. The station at Bhubaneswar $\left(20.1^{\circ} \mathrm{N}, 85.1^{\circ} \mathrm{E}\right)$ is situated near the center of the depression, whereas another land station Chennai $\left(13.0^{\circ} \mathrm{N}, 80.1^{\circ} \mathrm{E}\right)$ is far away from the storm center. The vertical profiles of meteorological variables $(u, v, \mathrm{EPT}$ and $\mathrm{RH})$ are plotted in figure 10 and figure 11 for the NCEP reanalysis and the high-resolution analysis respectively. A dramatic improvement in the profiles of wind components is clearly seen in the top two panels of figure 10. The other two panels at the bottom show that the high-resolution analysis is able to capture the vertical structure of the thermo- 
a) NCEP

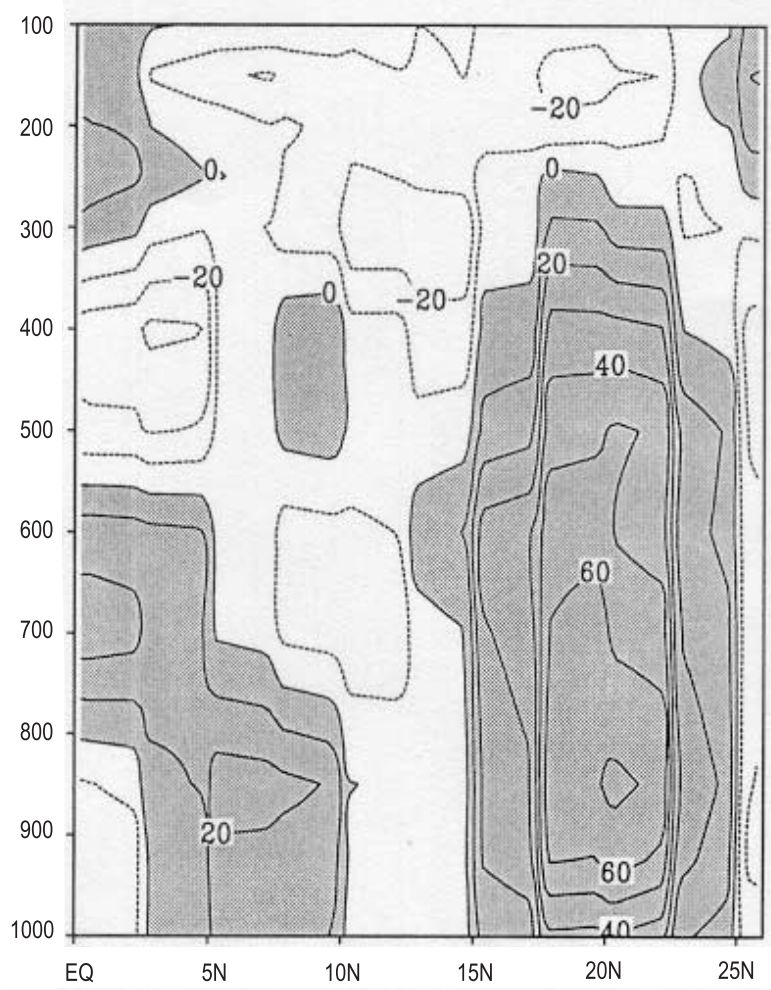

c) NCEP

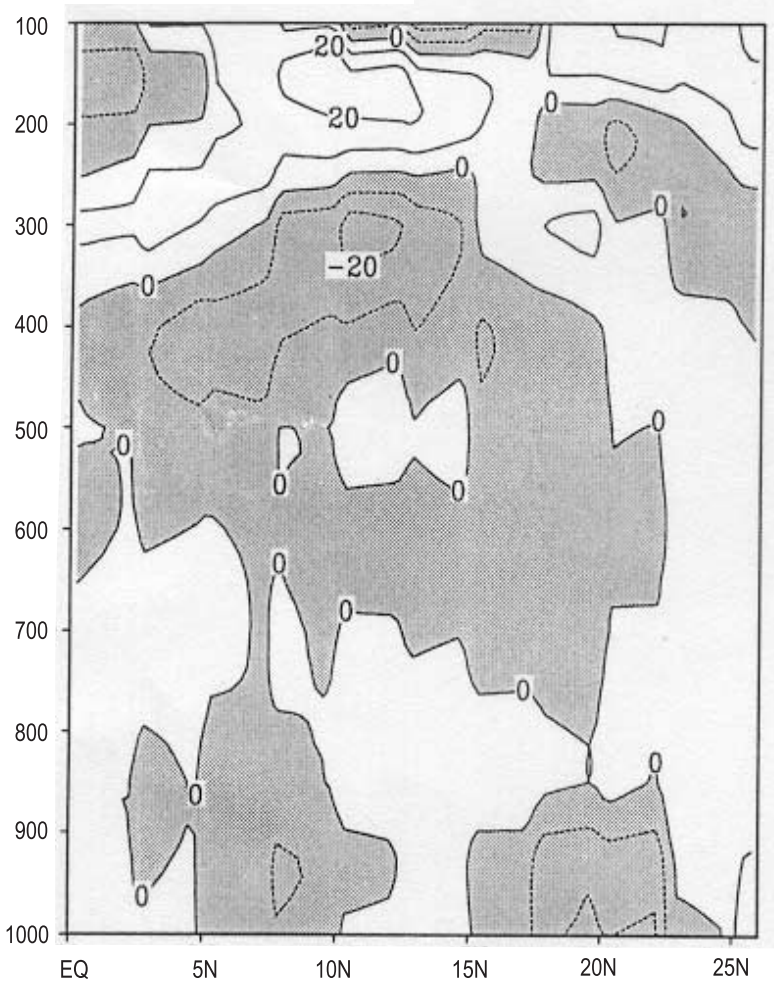

b) HRES

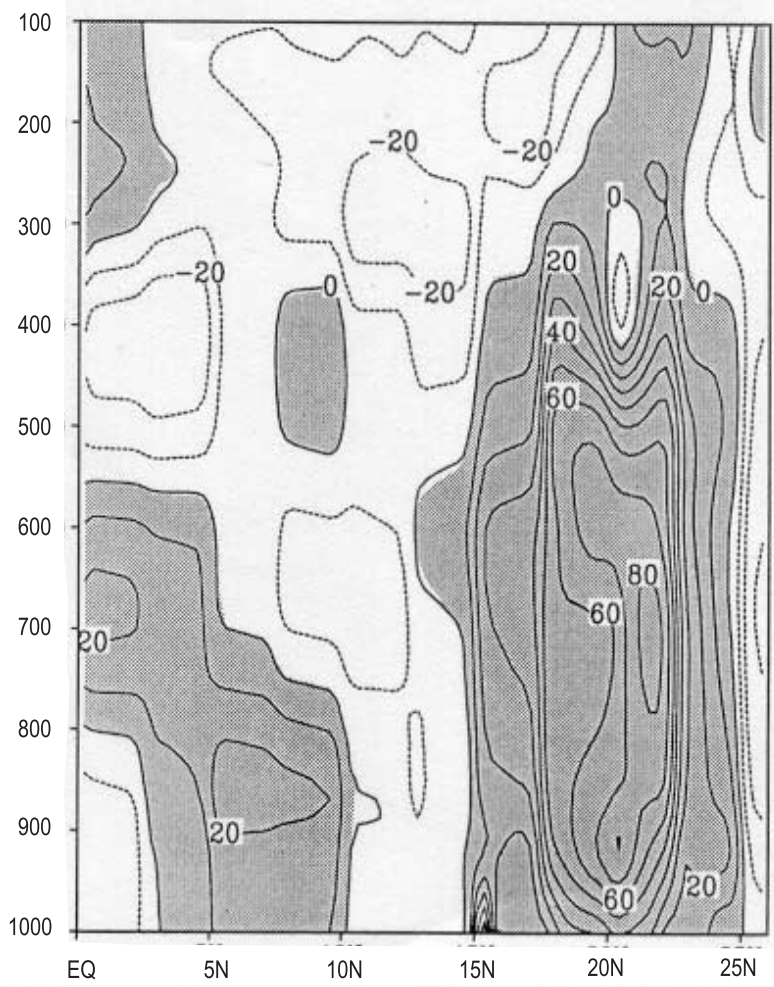

d) HRES

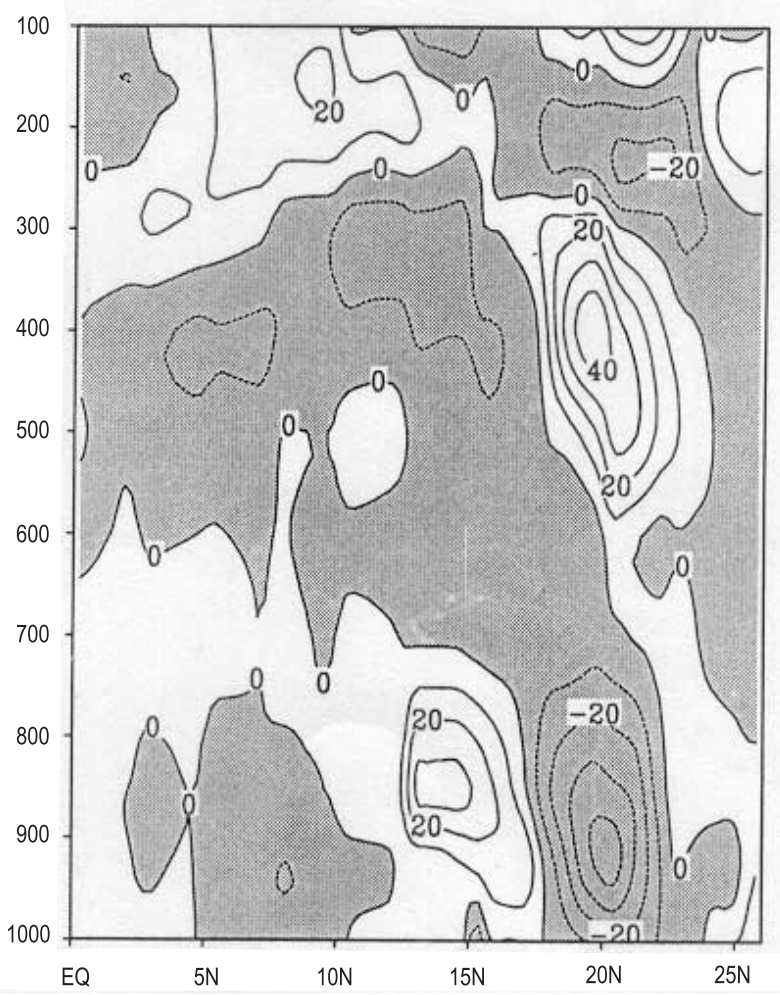

Figure 8. Vertical cross section of vorticity and divergence along $88.0^{\circ} \mathrm{E}$. (a) and (b) Vorticity $\left(10^{-6} \mathrm{~s}^{-1}\right)$, (c) and (d) Divergence $\left(10^{-6} \mathrm{~s}^{-1}\right)$. 
a) NCEP

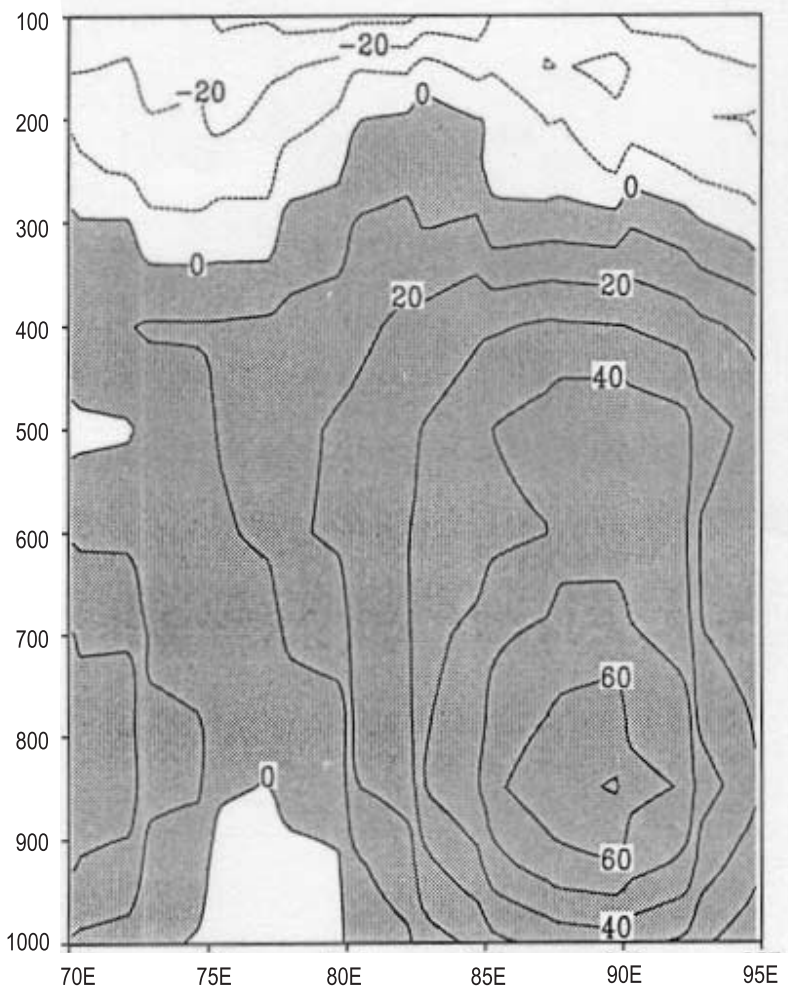

c) NCEP

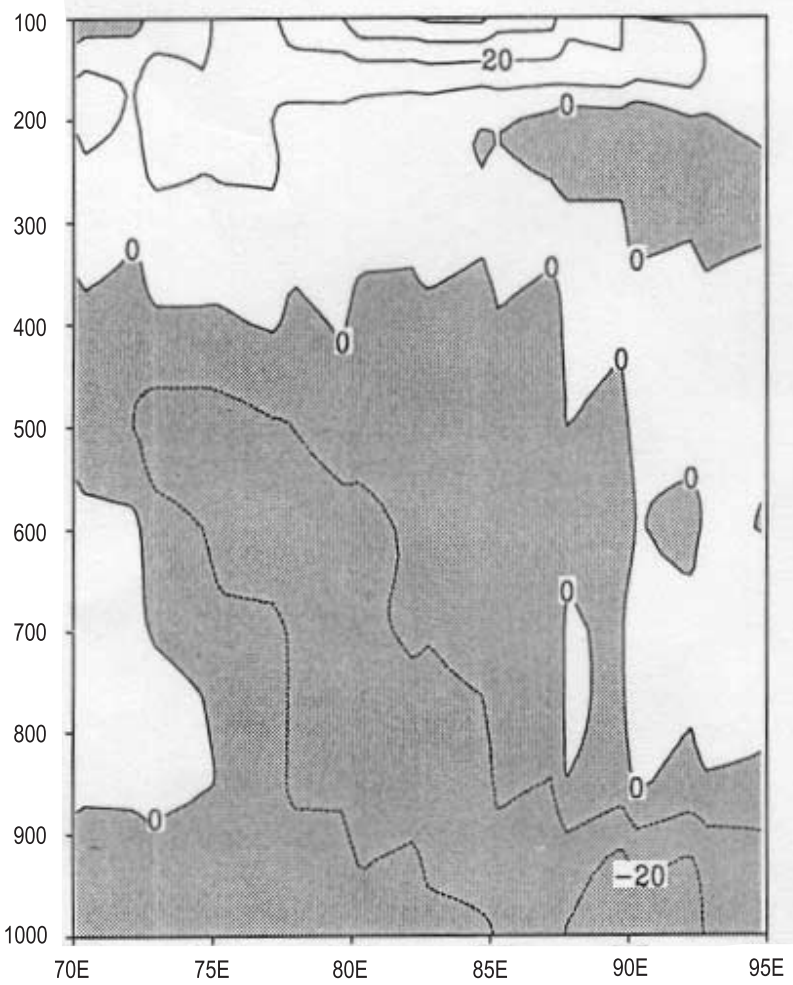

b) HRES

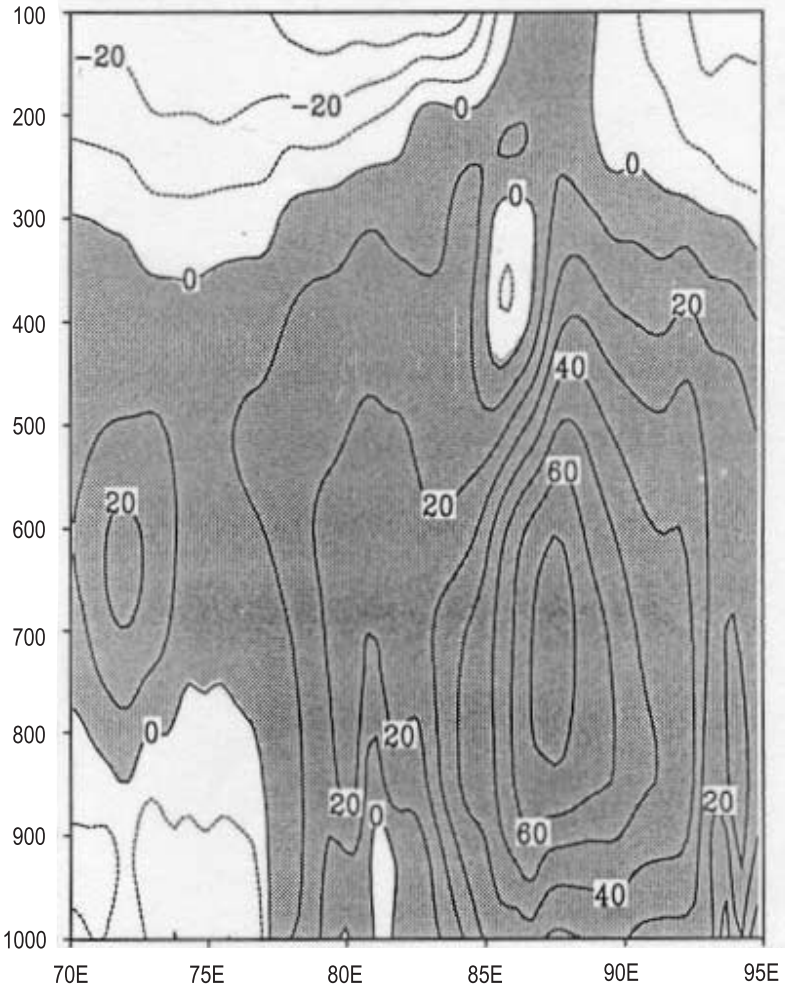

d) HRES

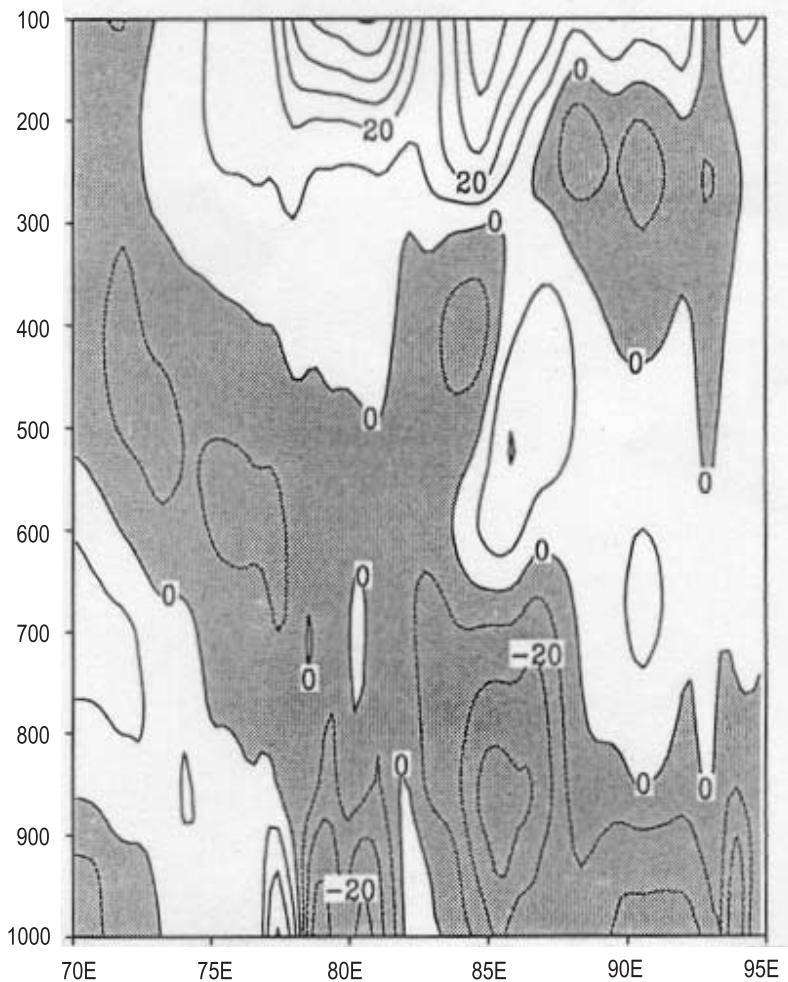

Figure 9. Vertical cross section of vorticity and divergence along $22.0^{\circ}$ N. (a) and (b) Vorticity $\left(10^{-6} \mathrm{~s}^{-1}\right),(\mathbf{c})$ and $(\mathbf{d})$ Divergence $\left(10^{-6} \mathrm{~s}^{-1}\right)$. 
a)

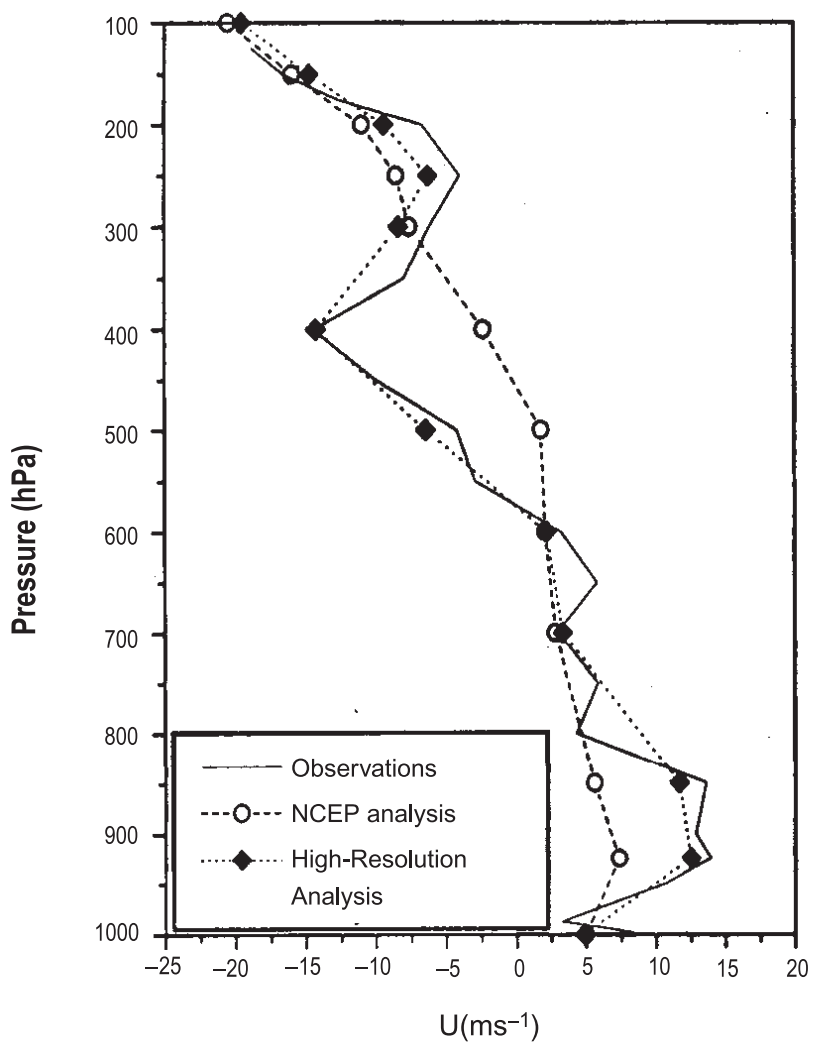

c)

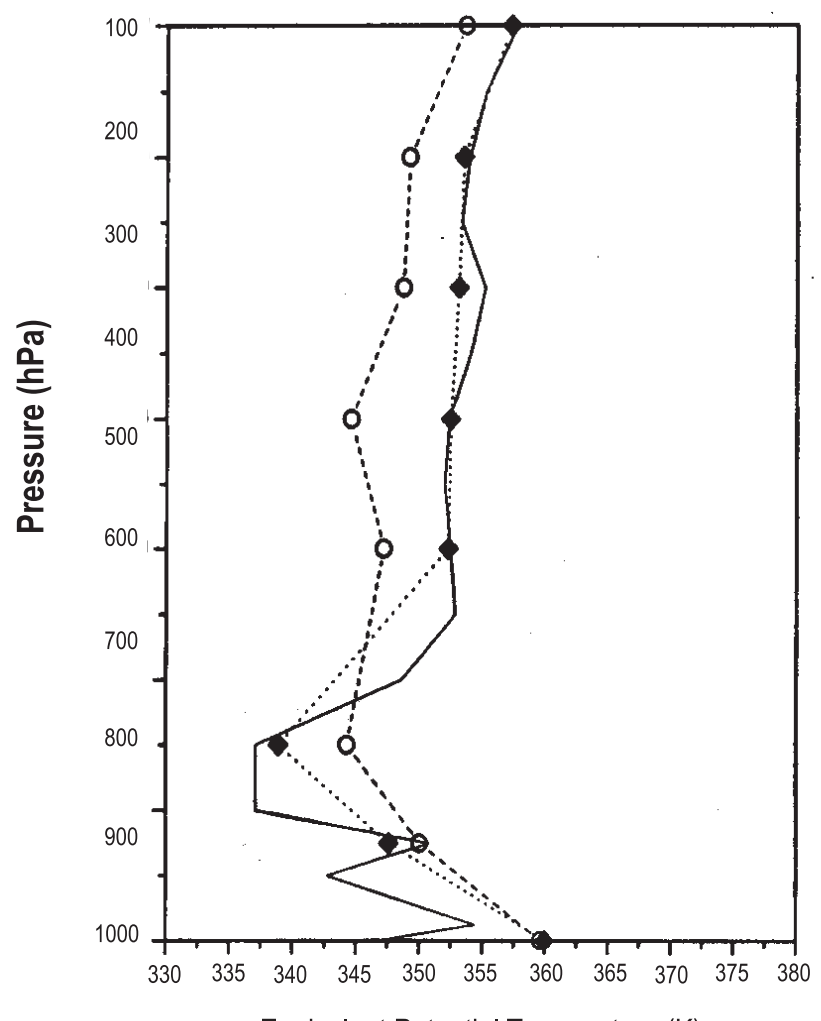

Equivalent Potential Temperature (K) b)

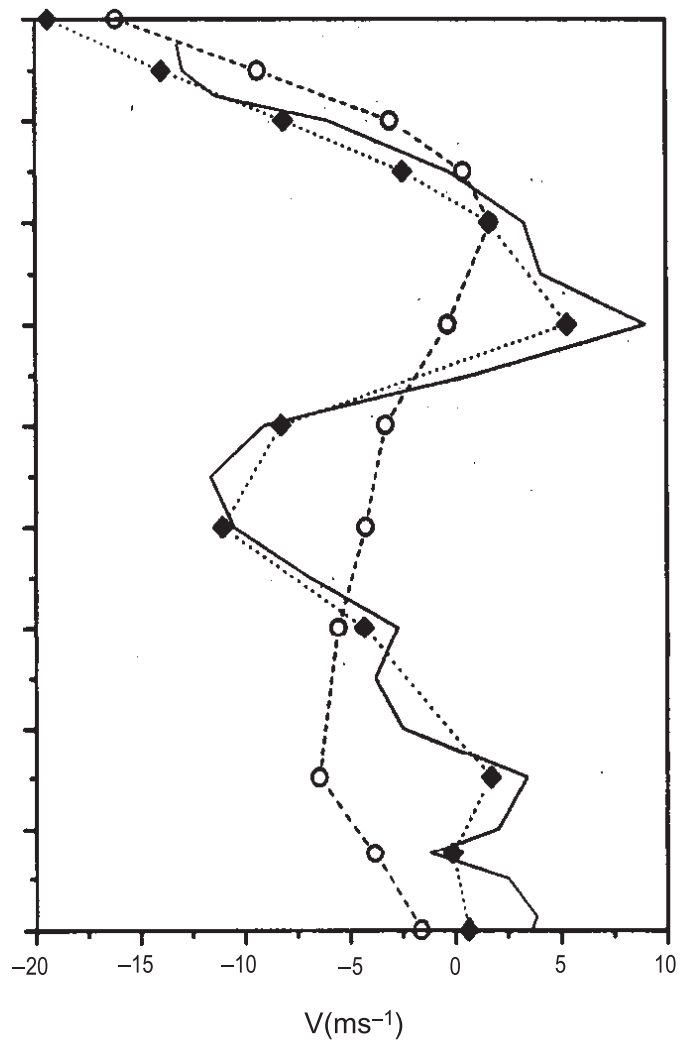

d)

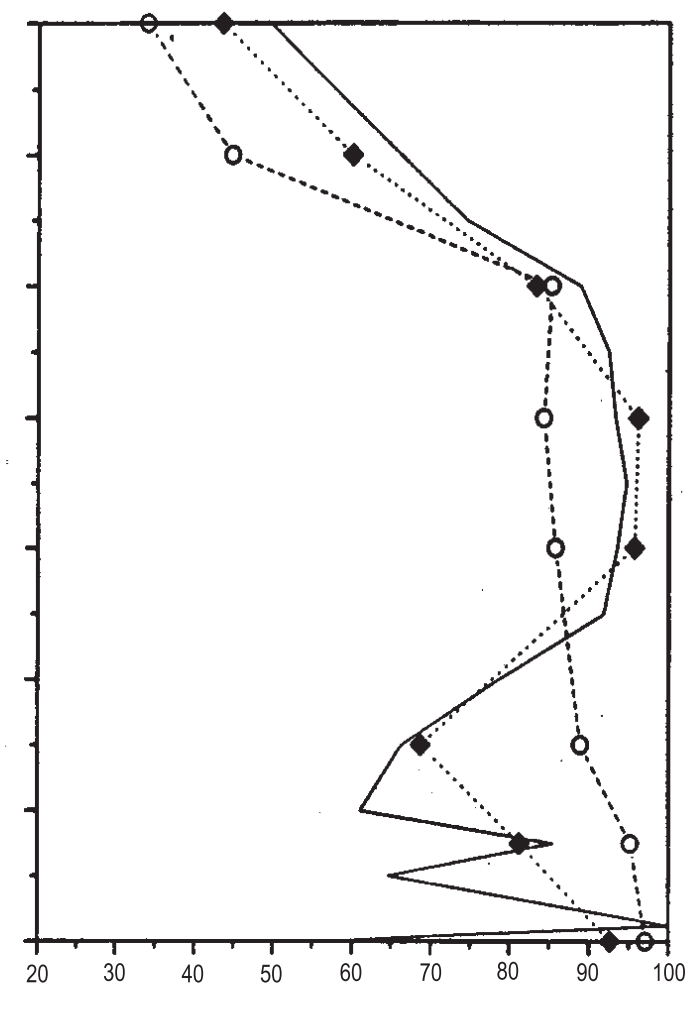

Relative Humidity (\%)

Figure 10. Vertical profiles of meteorological variables at Bhubaneswar $\left(20.1^{\circ} \mathrm{N}, 85.1^{\circ} \mathrm{E}\right)$. (a) U-Component, (b) V-Component, (c) Equivalent temperature and (d) Relative humidity. 
a)

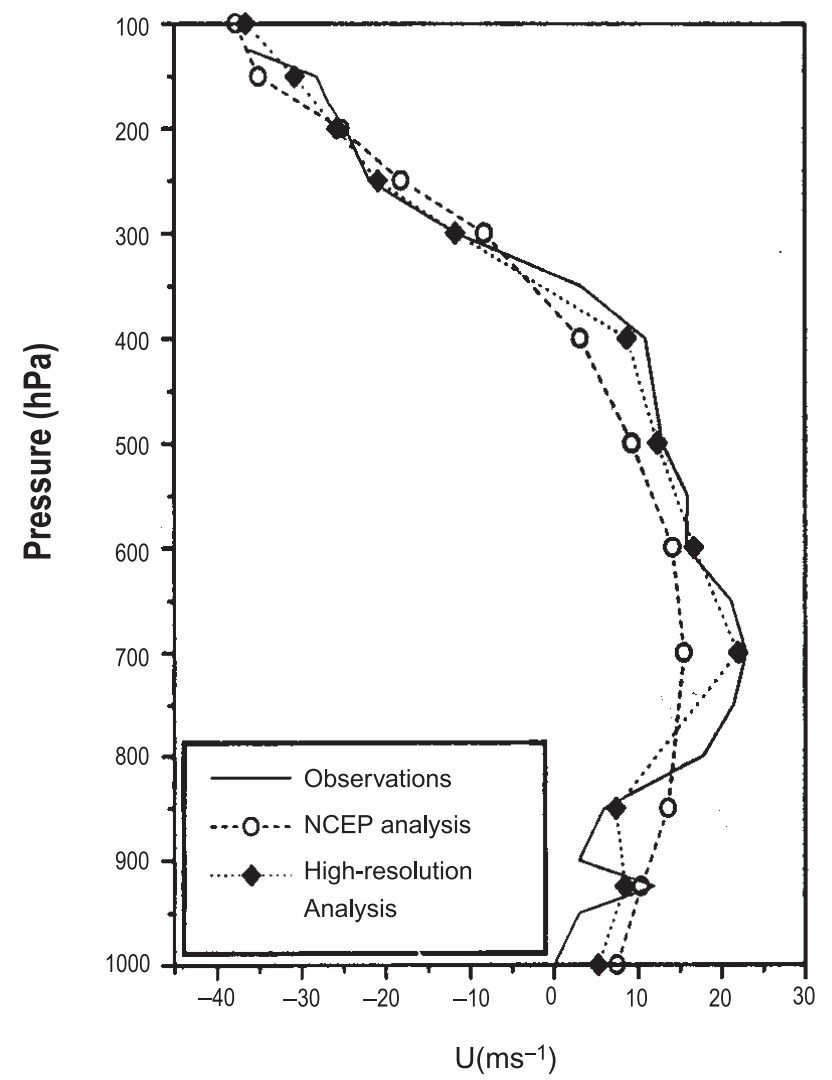

c)

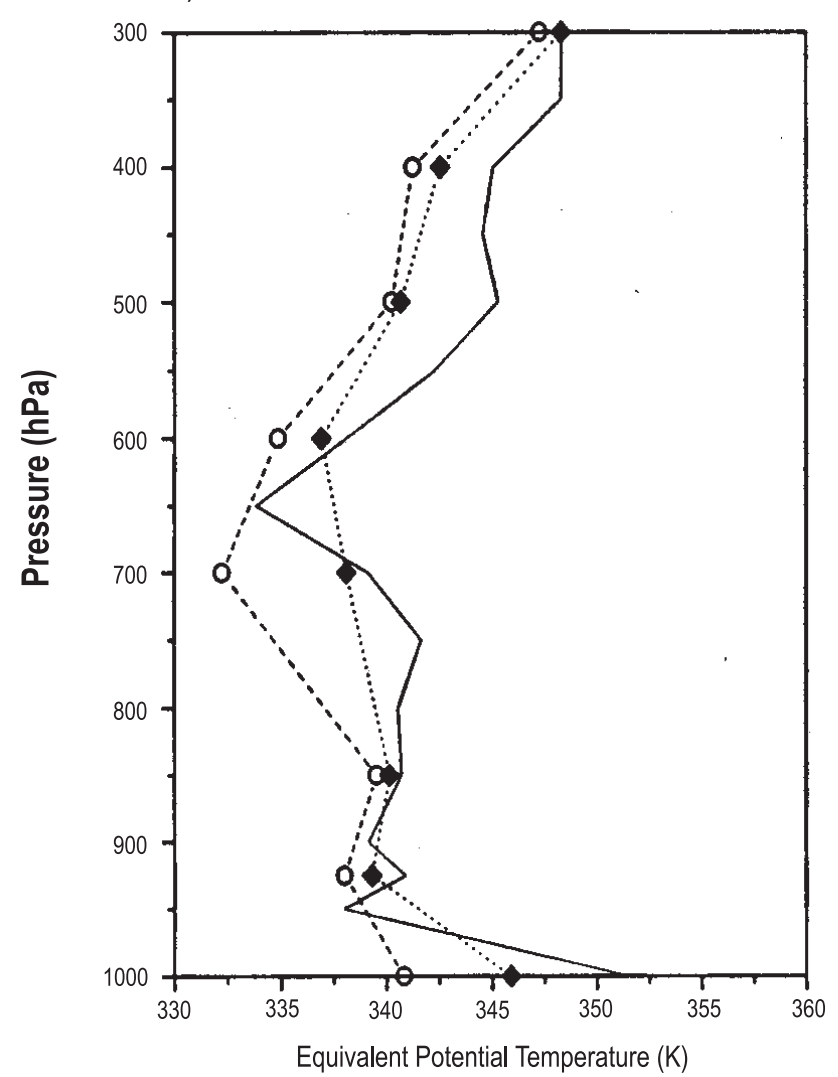

b)

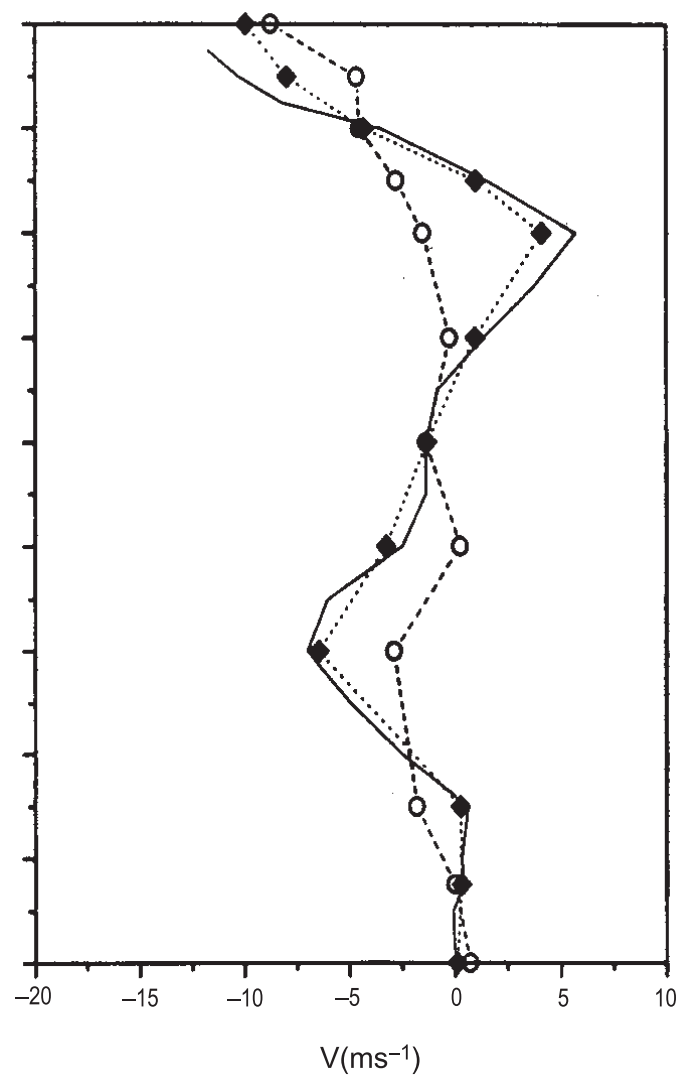

d)

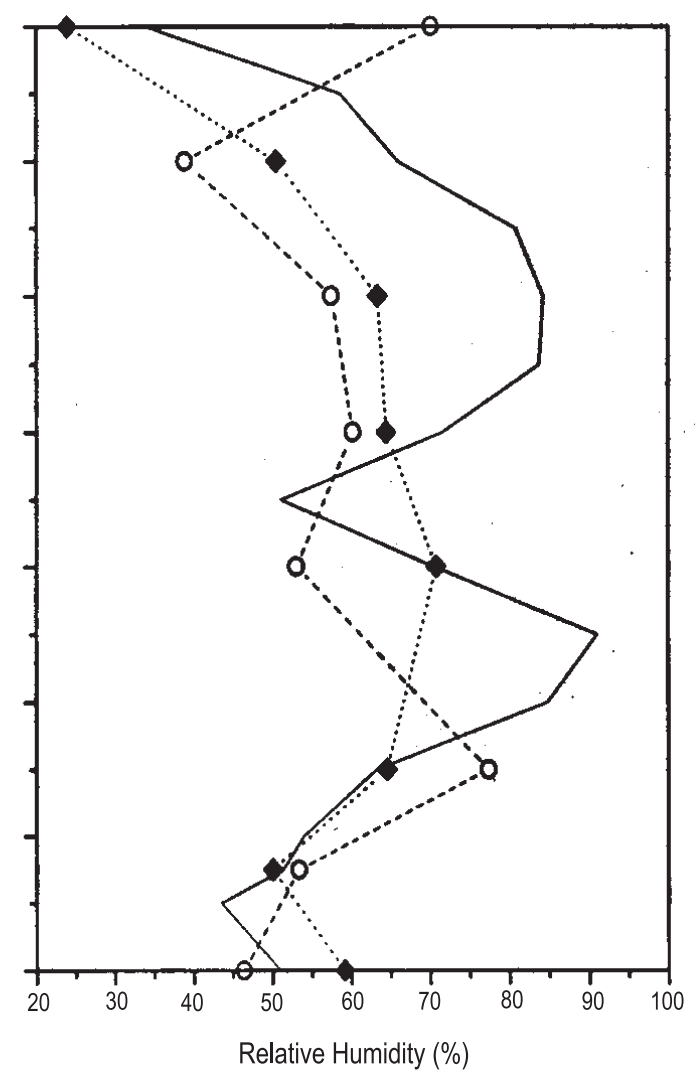

Figure 11. Same as figure 10 but for Chennai $\left(13 \cdot 0^{\circ} \mathrm{N}, 80.1^{\circ} \mathrm{E}\right)$. 
Table 1. Root mean square errors at different pressure levels.

\begin{tabular}{|c|c|c|c|c|c|c|c|c|}
\hline \multirow[b]{3}{*}{$\begin{array}{l}\text { Pressure } \\
\text { levels } \\
(\mathrm{hPa})\end{array}$} & \multicolumn{8}{|c|}{ Root mean square errors } \\
\hline & \multicolumn{2}{|c|}{$\begin{array}{l}\text { Temperature } \\
(\mathrm{K})\end{array}$} & \multicolumn{2}{|c|}{$\begin{array}{c}\text { Relative humidity } \\
(\%)\end{array}$} & \multicolumn{2}{|c|}{$\begin{array}{l}\text { Zonal component of } \\
\text { the wind }\left(\mathrm{ms}^{-1}\right)\end{array}$} & \multicolumn{2}{|c|}{$\begin{array}{l}\text { Meridional component } \\
\text { of the wind }\left(\mathrm{ms}^{-1}\right)\end{array}$} \\
\hline & $\begin{array}{c}\text { NCEP } \\
\text { Reanalysis }\end{array}$ & $\begin{array}{l}\text { High- } \\
\text { resolution } \\
\text { analysis }\end{array}$ & $\begin{array}{c}\text { NCEP } \\
\text { Reanalysis }\end{array}$ & $\begin{array}{l}\text { High- } \\
\text { resolution } \\
\text { analysis }\end{array}$ & $\begin{array}{l}\text { NCEP } \\
\text { Reanalysis }\end{array}$ & $\begin{array}{l}\text { High- } \\
\text { resolution } \\
\text { analysis }\end{array}$ & $\begin{array}{l}\text { NCEP } \\
\text { Reanalysis }\end{array}$ & $\begin{array}{l}\text { High- } \\
\text { resolution } \\
\text { analysis }\end{array}$ \\
\hline 850 & 2.162 & 2.192 & 14.256 & 10.303 & 4.873 & 4.194 & 4.250 & 3.429 \\
\hline 700 & 1.708 & 1.210 & 8.311 & 7.229 & 4.126 & 2.950 & 3.058 & 2.734 \\
\hline 500 & 1.566 & 1.362 & 9.761 & 7.639 & 3.600 & 2.133 & 2.985 & 2.203 \\
\hline 300 & 2.720 & 2.215 & 12.225 & 6.837 & 3.579 & 2.231 & 3.579 & 2.799 \\
\hline
\end{tabular}

dynamic variables, though there are some random fluctuations in the lower troposphere. It is clearly seen that the profiles are closer to observations in case of high-resolution analysis compared to the low-resolution NCEP reanalysis. Again, in figure 11 the profiles of wind components in the high-resolution analysis show a better agreement with the observation. The trends of EPT and relative humidity are better followed by the high-resolution analysis compared to the NCEP reanalysis.

Root mean square (r.m.s.) errors for different variables are computed for both the analysis against upper-air observations taken at thirty-one stations in the specified domain. The values of basic variables are specified at the observation points through bi-linear interpolation, and have been utilized for r.m.s error calculation. The root mean square errors at different levels are provided in table 1 . The improvements in the wind fields are distinct with a maximum r.m.s. error difference of $1.5 \mathrm{~ms}^{-1}$ between two analyses. The errors are also reduced significantly in all pressure levels in case of temperature as well as for relative humidity. Overall error statistics show that the highresolution analysis produced reasonably less errors compared to the NCEP reanalysis. As the number of observation points is less in some levels, the errors are large and the performance of the high-resolution analysis is apparently poor i.e., at $850 \mathrm{hPa}$. The imperfect first guess at grid points, random observational error and errors due to interpolation are the different sources of errors besides the computational error in the high-resolution analysis scheme (Franke 1985). In spite of that, the high-resolution analysis scheme gives better results quantitatively.

\section{Conclusions}

This paper describes an objective scheme to provide high-resolution analysis. A feature specific study has been carried out to assess the performance of high-resolution analysis for prominent synoptic and convective features associated with monsoon depression. The results indicate that the overall quality of the high-resolution analysis, generated through the multiquadric interpolation technique is improved substantially compared to the low-resolution NCEP reanalysis. After a successful insertion of conventional data as well as additional asynoptic observations, the analyzed data with increased horizontal resolution could produce the desired deep convective signatures of the specified weather event, which are consistent in the large-scale flow. The vertical profiles of basic meteorological variables have also been validated with the help of observations at two different land stations. A quantitative approach indicates that the vertical structure of wind components and thermodynamics variables presented by the highresolution analysis is more close to observations. Root mean square errors decreased in the highresolutions analysis in a fairly improvised manner. As the interpolation procedure involved in the error computation introduces additional errors, using an efficient interpolation process from the grid to observation points should decrease the overall analysis errors. The vertical resolution in the resultant analysis has not been increased compared to the first guess analysis. Hence, this factor prevents the final analysis to accentuate some significant features of the specific meteorological event. Further improvement in the analysis scheme is required to incorporate a technique for higher vertical resolution.

\section{Acknowledgements}

The authors sincerely acknowledge the Council of Scientific and Industrial Research (CSIR) for granting partial financial support and the Department of Science and Technology, (DST), Govt. of India for providing support to obtain the 
BOBMEX-99 dataset. We are thankful to the scientific team onboard ORV Sagar Kanya in particular, Prof. G S Bhat for contributing a part of the BOBMEX-99 dataset. We acknowledge the India Meteorological Department (IMD) for providing their surface and upper-air observations, and are also thankful to the National Center for Medium Range Weather Forecasting (NCMRWF), New Delhi for providing its facilities. We are grateful to the anonymous referee for his valuable comments and suggestions.

\section{References}

Barnes S L 1964 A technique for maximizing details in numerical weather map analysis; J. Appl. Meteorol. 3 369-409

Benjamin S G and Seaman N L 1985 A simple scheme for objective analysis in curved flow; Mon. Weather Rev. 113 $1184-1198$

Caracena F 1987 Analytic approximation of discrete filed samples with weighted sums and gridless computation of field derivatives; J. Atmos. Sci. 44 3753-3768

Cressman G P 1959 An operational objective analysis system; Mon. Weather Rev. 87 367-374

Franke R 1985 Sources of error in objective analysis; Mon. Weather Rev. 113 260-270

Godbole R V 1977 The composite structure of the monsoon depression; Tellus 29 25-40

Halberstam I and Tung S 1984 Objective analysis using Hough vectors evaluated at irregularly spaced locations; Mon. Weather Rev. 112 1804-1817

Hardy R L 1971 Multiquadric equations of topography and other irregular surfaces; J. Geophys. Res. 76 1905-1915
Keshavamurty R N and Rao M S 1992 The physics of monsoons (New Delhi: Allied Publishers Limited) 39-50

Krishnamurti T N, Bedi H S and Han W 1998 Organization of convection and monsoon forecasts; Meteorol. Atmos. Phys. 67 117-134

Lorenc A C 1981 A global three dimensional multivariate statistical interpolation scheme; Mon. Weather Rev. 109 701-721

Mapes B and Robert A H J 1992 An integrated view of the 1987 Australian monsoon and its mesoscale convective systems. I: Horizontal structure; Q. J. R. Meteorol. Soc. 118 927-963

Nuss W A and Titley D W 1994 Use of multiquadric interpolation for meteorological objective analysis; Mon. Weather Rev. 122 1611-1631

Parrish D F and Derber J C 1992 The national meteorological center's spectral statistical-interpolation analysis system; Mon. Weather Rev. 120 1747-1763

Ramage C S 1971 Monsoon meteorology (London: Academic Press) 45-46

Sasaki Y 1958 An objective analysis based on the variational method; J. Met. Soc. Japan 36 77-88

Sasaki Y 1969 Proposed inclusion of time variation terms, observational and theoretical, in numerical variational objective analysis; J. Met. Soc. Japan 47 115-124

Schlatter T W 1975 Some experiments with a multivariate statistical analysis scheme; Mon. Weather Rev. 103246 257

Talagrand O and Courtier P 1987 Variational assimilation of meteorological observations with the adjoint vorticity equations. Part - I, Theory; Q. J. R. Meteorol. Soc. 113 $1311-1328$

Thapliyal V, Desai D S and Krishnan V 2000 Cyclones and depressions over north Indian Ocean during 1999; Mausam 51, 3 215-224

Wu Y, Raman S and Mohanty U C 1999 Numerical investigation of the Somali jet interaction with the Western Ghat mountains; Pure appl. Geophys. 154 365-396 